ISSN: 0213-2052 - eISSN: 2530-4100

DOI: http://dx.doi.org/10.14201/shha201937285331

\title{
FRANCISCO PÉREZ BAYER COMO INFORMADOR DE ALEJANDRO JAVIER PANEL Y APUNTES SOBRE INSCRIPCIONES ROMANAS DE LA PROVINCIA DE SALAMANCA
}

\section{Francisco Pérez Bayer as Alejandro Javier Panel's Informant and Some Notes on Roman Inscriptions from the Salamanca Province}

María del Rosario HERNANDO SOBRINO

Universidad Complutense de Madrid. Archivo Epigráfico de Hispania ${ }^{1}$ mrhernando@ghis.ucm.es

Fecha de recepción: 12-11-2018; aceptación definitiva: 28-2-2019

RESUMEN: Tras repasar de modo sucinto la carrera de Francisco Pérez Bayer, una de las más importantes figuras de la escena cultural hispana del siglo XVIII, analizamos su labor en el ámbito de la epigrafía y su relación, en calidad de informador, con Alejandro Javier Panel. Pérez Bayer proporcionó al jesuita francés apuntes sobre numerosos epígrafes, epígrafes que este último integró en su corpus, inconcluso, de inscripciones romanas de Hispania; los apuntes relativos a diversas piezas salmantinas, conservados

1. Este trabajo está adscrito al proyecto Docemus-CM (S2015-HUM/3377) de la Comunidad de Madrid, a los proyectos del MINECO (Gobierno de España) Cithara (HAR2015-65649-C2-1-P) y Nuevas bases documentales para el estudio histórico de la Hispania romana en época republicana: onomástica y latinidad (III-I a. C.) (HAR201566463-P), así como al Grupo de investigación UCM Ciudades Romanas (Grupo 930692). 
entre los manuscritos de Panel y casi desconocidos, dan buena muestra de la calidad del trabajo del valenciano en materia epigráfica.

Palabras clave: Manuscritos; Epigrafía latina.

ABSTRACT: After briefly reviewing the career of Francisco Pérez Bayer, one of the most important figures of the Hispanic cultural scene of the $18^{\text {th }}$ century, we analyse his work in the field of epigraphy and his relationship, as an informant, with Alejandro Javier Panel. Pérez Bayer provided the French Jesuit with notes about numerous epigraphs, epigraphs that Panel then integrated into his inconclusive corpus of Roman inscriptions of Hispania. Among the manuscripts of Panel, his notes related to various pieces of Salamanca are almost unknown, but are a good sample of the quality of the Valencian's epigraphic work.

Keywords: Manuscripts; Latin Epigraphy.

\section{INTRODUCCIÓN: ALGUNOS DATOS SOBRE LA CARRERA Y OBRA DE FRANCISCO PÉREZ BAYER}

Francisco Pérez Bayer (Valencia 1711-1794) fue, sin duda, una de las figuras más relevantes de la escena cultural del siglo XVIII ${ }^{2}$; su preparación,

2. Para la vida y obra de Pérez Bayer son fundamentales, entre otros, los trabajos de Sempere y Guarinos, J.: Ensayo de una biblioteca española de los mejores escritores del reinado de Carlos III. Madrid, 1785 (facsímil, Salamanca, 1997), vol. I, pp. 189-202; PASTOR Fuster, J.: Elogio histórico y bibliográfico del ilustrísimo señor Don Francisco Pérez Bayer, del Consejo y Cámara de Castilla, caballero pensionado de la Real y distinguida Orden de Carlos III, preceptor de los serenísimos Infantes, arcediano mayor y canónigo de Valencia y bibliotecario de su Majestad. Valencia, imprenta de Ildefonso Mompié (facsímil 1991); id.: Biblioteca Valenciana de los escritores que florecieron hasta nuestros dias y que aún viven. Con adiciones y enmiendas á la de D. Vicente Ximeno. Tomo segundo. Valencia, imprenta de Ildefonso Mompié, pp. 141-162; Juan García, L.: Pérez Bayer y Salamanca. Datos para la bio-bibliografía del hebraísta valenciano. Salamanca, 1918; MATEu y Llopis, F.: En torno de Pérez Bayer, numísmata y bibliotecario, Discurso de ingreso en el Centro de Cultura Valenciana, 30 de noviembre de 1950. Valencia, 1953; Agullar Piñal, F.: Bibliografía de autores españoles del siglo XVIII. Madrid, 1991, vol. VI, pp. 353-362; Mora, G.: "Francisco Pérez Bayer", en Ayarzagüena SAnz, M. y Mora, G. (eds.): Pioneros de la arqueología en España. Del siglo XVI a 1912 (Zona Arqueológica 3). Alcalá de Henares, 2004, pp. 47-49; $i d$.: "Pérez Bayer, Francisco", en Díaz-Andreu, M., Mora, G. y Cortadella, J. (coords.): Diccionario histórico de la Arqueología en España (siglos XV-XX). Madrid, 2009, pp. 515517. Como bien destaca Mestre Sanchís, carecemos de una buena biografía sobre tan importante figura (en Mestre Sanchís, A., Pérez García, P. y Catalá Sanz, J. A. (eds.): Francisco Pérez Bayer. Viajes literarios (Arxius i Documents 22). Valencia, 1998, p. 10), por lo que resulta fundamental el correspondiente volumen del epistolario de Gregorio Mayans (MAYANs 
Y APUNTES SOBRE INSCRIPCIONES ROMANAS DE LA PROVINCIA DE SALAMANCA

su capacidad de trabajo, su innegable habilidad para sortear el cambiante panorama político y su longevidad contribuyeron a que, efectivamente, forjase una de las carreras más completas y exitosas de la centuria.

Cuando, en el invierno de 1733, Pérez Bayer llegó a Salamanca desde su Valencia natal, lo hizo "siendo ya ordenado in sacris, Bachiller teólogo y artista [i.e., bachiller en la Facultad de Artes] de Gandía, con cuatro cursos de leyes aprobados en Valencia " ${ }^{3}$; prosiguió sus estudios como jurista en la Universidad de Salamanca, si bien se graduaría en la Universidad menor de El Burgo de Osma. De regreso en Salamanca (1737), comenzó a opositar y, al mismo tiempo, formó parte de la Academia de juristas del Colegio Trilingüe o de San Jerónimo y se encargó, de modo altruista, de la organización del archivo del cabildo catedralicio de la ciudad. De Salamanca partió en 1738 con destino a Valencia, donde trabajó como secretario de cartas y visitas del arzobispo Andrés Mayoral, cuyo círculo era de marcado carácter escolástico y colegial; posteriormente, ganó la cátedra de hebreo -lengua que había aprendido de modo autodidacta- en la Universidad de Valencia (1745), la misma que, un año después, y con no pocas dificultades, obtuvo en Salamanca.

Para la consecución de la cátedra de hebreo salmantina -y aún para el incardinamiento de la misma en la Facultad de Artes y no en la de Teología, una vez obtenida ${ }^{4}$ - parece que, además de la recomendación de Gregorio Mayans ${ }^{5}$, fue capital el apoyo prestado por colegiales y jesuitas (entre ellos Alejandro Javier Panel), quienes también le franquearon el acceso a los jesuitas Jacques Antoine Fèvre y Francisco Rávago, confesores de Fernando VI y, por lo mismo, directores de la recién creada Real Librería de modo consecutivo. No debe extrañar, por tanto, que una vez que

y SISCAR, G.: Epistolario, VI: Mayans y Pérez Bayer. Valencia, 1977 [transcripción, notas y estudio preliminar A. Mestre Sanchís]); nosotros hemos utilizado aquí la versión que consta en los valiosísimos fondos de la Biblioteca Valenciana Digital.

3. Juan García, 1918, p. 10; del mismo autor han sido tomados buena parte de los datos que siguen.

4. Que le hubiese obligado a obtener el grado de maestro en Teología. Se trató de una agria disputa -más política que intelectual- en la que los detractores de Pérez Bayer (la inmensa mayoría del claustro salmantino y, fundamentalmente, los mercedarios), hubieron de acatar finalmente una Real Orden emitida por Fernando VI el 13 de abril de 1747, dando la razón al valenciano.

5. Que ya le había favorecido para la cátedra previa en Valencia (véase, a este respecto, la carta escrita por Pérez Bayer a Mayans, en que da cuenta de su obtención, fechada el 24 de febrero de 1745; MAYANS y SisCar, 1977, n. ${ }^{\circ}$ 64, pp. 73-74). Para las recomendaciones de cara a la cátedra de Valencia son de interés las cartas n. ${ }^{\circ} 87,88,89$, todas datadas en junio de 1746 (ibid.: 109-110, 110-111, 111-113, respectivamente); la oposición es narrada por extenso en carta de septiembre del mismo año (ibid.: n. ${ }^{\circ}$ 93, 115-121). 
la denominada Junta del Real Patronato (integrada por José de Carvajal y Lancaster, ministro secretario de Estado, el ya citado Francisco Rávago, el marqués de los Llanos, el abad de la Trinidad de Orense y don Jacinto de la Torre) formó la Comisión de Archivos que habría de encargarse de buscar la documentación favorable a la causa del regalismo ${ }^{6}$, Pérez Bayer fuese nombrado colaborador del jesuita conquense Andrés Marcos Burriel, a quien se había encomendado la dirección de tal Comisión en 1749. La Universidad de Salamanca, "harta [...] de tantas discusiones acerca de su catedrático" ${ }^{7}$ y sabedora de sus apoyos, le otorgó la correspondiente dispensa.

No obstante, el valenciano solo participó en el proyecto de la Comisión de Archivos durante un año, como Burriel explicita en una carta a Gregorio Mayans ${ }^{8}$; durante este tiempo ambos -Burriel y Pérez Bayer, que ya se conocían personalmente o, al menos, habían mantenido una relación epistolar- se encargaron de investigar los archivos catedralicios de la ciudad de Toledo?. De este periodo toledano fue fruto la primera obra conocida del valenciano, De toletano hebraeorum templo ${ }^{10}$.

6. Para este aspecto véase Mora, G.: Historias de mármol. La arqueología clásica española en el siglo XVIII (Anejos de AEspA, 18). Madrid, 1998, pp. 41-48.

7. Juan García, 1918, p. 99.

8. "pues Bayer estuvo un año y sólo copió de mi orden" (carta 305, de 2 de abril de 1756, en MAYANS y Siscar, G.: Epistolario, II: Mayans y Burriel. Valencia, 1972 [transcripción, notas y estudio preliminar A. Mestre], p. 615). En todas las citas textuales se respetará la puntuación y ortografía originales.

9. Aunque sin ser excesivamente generoso en datos, para esta etapa es muy útil el epistolario cruzado entre Burriel y Mayans (cf. MAYANS y SISCAR, 1972, citado en la nota precedente).

10. De esta obra, ilustrada con excelentes dibujos de Francisco Javier de Santiago Palomares y dedicada al confesor Rávago, se conservan dos copias en los fondos manuscritos de la Biblioteca Nacional de España -en adelante BNE- (Mss. 8260 y 9296, de 1752). Como bien indica Mora, en ella Pérez Bayer manifestaba ya su interés por el que sería su tema preferido: "la lengua y el alfabeto hebreos como origen de los alfabetos fenicio y griego y base para descifrar las escrituras "desconocidas"” (MORA, G.: "La "erudita peregrinación”. El viaje arqueológico de Francisco Pérez Bayer a Italia (1754-1759)", en Beltrán Fortes, J. et alii (eds.): Illuminismo e Ilustración. Le antichità e $i$ loro protagonisti in Spagna e in Italia nel XVIII secolo (Bibliotheca Italica, Monografías de la Escuela Española de Historia y Arqueología en Roma 27). Roma, 2003, p. 258); un tema, añadimos, que ya le ocupaba en su segunda etapa salmantina (véanse las cartas enviadas a Mayans sobre el mismo, ya desde Salamanca, en MAYans y SISCAR, 1977, n. ${ }^{\circ}$ 95-96, pp. 123-124, pp. 125-131, respectivamente, o la carta que Burriel remitió a Mayans en octubre de 1748, en MAYANS y SisCAR, 1972, n. ${ }^{\circ} 132$, p. 410). Si nuestros datos son correctos, De toletano hebraeorum... permanece aún inédita, "sin que sea fácil explicar el porqué" (CASANOvAS Miró, J.: Epigrafía hebrea [Real Academia de la Historia. Catálogo del Gabinete de Antigüedades I. Antigüedades 1.1.5]. Madrid, 2005, p. 16). 
MARÍA DEL ROSARIO HERNANDO SOBRINO

FRANCISCO PÉREZ BAYER COMO INFORMADOR DE ALEJANDRO JAVIER PANEL

Y APUNTES SOBRE INSCRIPCIONES ROMANAS DE LA PROVINCIA DE SALAMANCA

En 1752, Pérez Bayer obtuvo el canonicato de Barcelona ${ }^{11}$ y, poco después, una pensión de estudios en Italia ${ }^{12}$. Su comisión en Italia ${ }^{13}$ tenía diversos objetivos: perfeccionar las lenguas orientales (particularmente el árabe) ${ }^{14}$, recopilar cuantos manuscritos, monedas, inscripciones y piezas antiguas pudiese, y copiar o comprar libros, manuscritos y cartas de españoles en bibliotecas públicas y privadas de Italia $^{15}$. Se pretendía satisfacer así diferentes necesidades: de un lado, nutrir los fondos de la Real librería y de su Gabinete de Medallas y, de otro, recoger cuanto material pudiera ser útil "en fin a las órdenes históricas que se perseguían" ${ }^{16}$. Su estancia en Italia (1754-1759) coincidió con el cambio de situación política en España ${ }^{17}$

11. De dicha obtención dio puntual noticia a Mayans (MAYANS y SISCAR, 1977, n. ${ }^{\circ} 111$, pp. 147-148, carta de 25 de agosto de 1752). Durante su estancia en la Ciudad Condal publicará un pequeño tratado, de temática religiosa, titulado Reges Tharsis et insulae (cf. Pérez Bayer, F.: Reges Tharsis et insulae. Pro explanatione Davidici Psalmi: Deus iudicium tuum Regi da $E c$. ad amplissimum almae Barcinonensis Ecclesiae canonicorum collegium oratio postridie fest. S. Lucae XIV kal. Nov. salutis MDCCLIII habita. Barcelona, 1753, imprenta de Pablo Nadal); será su primera obra editada.

12. Oportunamente comunicada a Mayans en carta de 23 de abril de 1754 (MAYANS Y SISCAR, 1977 , n. ${ }^{\circ} 114$, pp. 150-152).

13. Analizada de modo particular por Catalá Sanz (en el estudio preliminar que consta en Mestre Sanchís, Pérez García y Catalá Sanz (eds.), 1998, pp. 60-68) y, especialmente, por Mora, 2003. Del viaje a Italia dan cuenta tanto su Diario específico (registrado en Mestre Sanchís, Pérez García y Catalá Sanz (eds.), 1998, pp. 651-674) como el epistolario de Mayans.

14. Sabemos por Manuel Martínez Pingarrón, amigo y confidente de Mayans, que Pérez Bayer recibió clases de árabe del sacerdote sirio maronita Miguel Casiri, quien se encargaría de catalogar los manuscritos árabes de El Escorial (MAYANS y SIsCAR, G.: Epistolario, VII: Mayans y Martinez Pingarrón, 1: Historia cultural de la Real Librería. Valencia, 1987 [transcripción, estudio preliminar y notas A. Mestre], n. ${ }^{\circ}$ 244, pp. 330-331, carta de 30 de enero de 1750).

15. Según narra el propio Pérez Bayer a Mayans en carta fechada el 23 de abril (en MAYANS Y SISCAR, 1977 , pp. 150-151).

16. JuAn GarCía, 1918, p. 116, aludiendo así a la ya citada causa del regalismo.

17. Cambio de situación que, para J. A. Catalá Sanz ("Pérez Bayer después del viaje a Italia", Estudis, 27, 2001, en especial pp. 229-237), explica la "inversión" de prioridades en el viaje de Pérez Bayer a Italia: los primigenios anhelos de mejorar su formación intelectual cedieron pronto su puesto a razones relacionadas con la supervivencia política y las posibilidades de promoción. Con esta nueva prioridad se vincula la edición de su obra Damasus et Laurentius... (cf. Pérez BAYER, F.: Damasus et Laurentius hispanis asserti et vindicati. Roma, 1756, imprenta de Giuseppe y Filippo de Rossi), destinada a mostrar el origen hispano de dichos santos; una obra de tinte nacionalista, por completo contraria a las ideas de Mayans (quien abiertamente lo indicó al autor cuando este le comunicó su preparación; cf. MAYANS Y SISCAR, 1977, n. ${ }^{\circ} 119$, pp. 164-167) y que Burriel no dudó en calificar de "mamarrachada" (MAYANS y SisCAR, 1972, n. ${ }^{\circ} 320$, p. 634, de octubre de 1756). Véase también, al respecto del cambio de actitud de Pérez Bayer, la opinión de Mestre Sanchís 
y le permitió, además de ampliar notablemente su círculo de amistades (hecho al que no fue ajeno Mayans), conocer y granjearse el afecto del futuro rey Carlos III en el curso de una visita a Nápoles ${ }^{18}$. Alejado del círculo jesuita y convertido ya en la cabeza visible de los manteístas, regresó a España para ocupar una canonjía en Toledo, con la dignidad de tesorero del cabildo catedralicio (1759).

Tras la llegada al trono de Carlos III (1759), Pérez Bayer pasó del canonicato de Toledo a El Escorial (1762), con la real encomienda de elaborar el catálogo de los manuscritos griegos, hebreos y latinos de su biblioteca ${ }^{19}$, que nunca llegaría a publicarse ${ }^{20}$. Si el afecto del monarca jugaba ya a su favor, el apoyo del nuevo secretario de Estado, Jerónimo Grimaldi (designado para tal cargo en 1763), y el nombramiento de Manuel de Roda -con quien Pérez Bayer había trabado amistad en Roma- como secretario de Gracia y Justicia (1765) propulsaron definitivamente su carrera. De hecho, el valenciano se convirtió en el personaje clave del cambio cultural impulsado por el nuevo monarca ${ }^{21}$ : expulsados ya los jesuitas, él ocupará

en el prólogo a MaYans y SISCAR, 1977, p. XXXIX, con quien concuerda MORA, 2003, pp. 260-261.

18. Pérez Bayer dio cuenta de este encuentro a Mayans en carta enviada desde Roma con fecha de 23 de abril de 1759 (MAYANS y SisCAR, 1977, n. ${ }^{\circ} 128$, pp. 199-201). Sobre el afecto que Carlos III profesó al valenciano, véase lo señalado por Mestre Sanchís en el prólogo a MaYANS y SISCAR, 1977, p. XXXIX.

19. Mayans se alegró mucho de tal destino, aunque sus palabras no tienen desperdicio: "Si consigue Vm. lo que desea, de hacer colecciones de obras, que no han salido a luz, de las lenguas eruditas i de la española, merecerá que le levanten un coloso de oro como ilustrador de los españoles en tiempo de tanta ignorancia. Yo empezaría por las españolas para instruir mejor a la nación, porque lo contrario es empezar a instruir a los estrangeros capaces de entender lo que está escrito en hebreo i griego" (MAYANS y SISCAR, 1977, n. ${ }^{\circ} 137$, pp. 211-214).

20. Juan García, 1918, p. 117, indica que en 1765 tenía ya muy adelantado el trabajo (cinco tomos y tres copias más); por su parte Blanco, P.: "Los manuscritos hebreos de la Biblioteca de El Escorial", BRAH, 95, 1929, p. 505, señala que "Lo que trabajase e hiciese Pérez Bayer en la formación del catálogo de manuscritos hebreos no he podido verlo, porque en esta Biblioteca no se conserva nada, pues todos sus manuscritos los legó a la ciudad de Valencia, con destino a la Universidad" (véase también, a este respecto, Mayans Y SISCAR, 1977, n. ${ }^{\circ}$ 226, pp. 362-364); parece que, efectivamente, tales manuscritos se perdieron en el incendio de la biblioteca de la Universidad de Valencia producido por el ataque de las tropas francesas en 1812. Para los manuscritos donados en julio de 1785 por Pérez Bayer a Valencia véase Cabeza Sánchez-Albornoz, M. C.: "Índice de los manuscritos donados por Pérez Bayer a la Universidad de Valencia", en Celestino Agudo, S. (ed.): De libros y bibliotecas. Homenaje a Rocío Caracuel. Sevilla, 1994, pp. 57-72.

21. A este respecto es de gran interés la introducción de Mestre Sanchís en MaYans y SISCAR, G.: Epistolario, VIII: Mayans y Martinez Pingarrón, 2: Los Manteístas y la cultura ilustrada. Valencia, 1988 [transcripción, estudio preliminar y notas A. Mestre]; una reciente 
Y APUNTES SOBRE INSCRIPCIONES ROMANAS DE LA PROVINCIA DE SALAMANCA

un puesto tradicionalmente desempeñado por los de dicho hábito, el de preceptor de los Infantes reales ${ }^{22}$ (desde 1766 hasta 1778) ${ }^{23}$; además, será el encargado de llevar a cabo el proyecto de reforma de los Colegios Mayores ${ }^{24}$

En 1775 obtuvo de Carlos III el nombramiento de arcediano titular de Valencia, pero con dispensa para seguir en Madrid a su servicio ${ }^{25}$. En el año 1781 publicó la que, según Juan García ${ }^{26}$, fue su obra favorita y la que mayor fama le proporcionó: De Numis hebraeo-samaritanis ${ }^{27}$, que hubo

síntesis en López Fonseca, A.: “La formación clásica de Francisco Pérez Bayer y los proyectos ilustrados: Ensayo, erudición y crítica en el siglo XVIII español", Torre de los Lujanes, 63, 2008, en especial pp. 180-183.

22. La primera noticia relativa a este nuevo encargo que encontramos en el epistolario cruzado por Pérez Bayer con Mayans data del 31 de agosto de 1767 (MAYANS y SISCAR, 1977, n. ${ }^{\circ}$ 177, pp. 307-308); ya Martínez Pingarrón había informado a Mayans sobre el particular el 14 de abril del mismo año (MAYANS y SISCAR, 1988, n. ${ }^{\circ} 17$, pp. 61-63).

23. Periodo registrado por Juan García, 1918, pp. 118-121; el mismo autor destaca también la benéfica influencia ejercida por Pérez Bayer sobre don Gabriel -alumno cuyo singular talento fue remarcado por el propio valenciano en numerosas misivas (cf. MaYans y SISCAR, 1977, n. ${ }^{\circ} 179$ y siguientes) - y, en especial, su esmerada dirección de la traducción que de las obras de Salustio hizo el citado infante, que vería la luz el 4 de noviembre de 1772. Completaba esta obra, por la que el valenciano obtuvo la Cruz de Carlos III, una suerte de disertación aneja, de su propia autoría, en la que la numismática y la epigrafía tienen, especialmente la primera, un gran protagonismo (cf. PÉrEz BAYER, F.: "Del alfabeto y lengua de los fenices y de sus colonias. Para ilustracion de un lugar de Salustio, en que hablando de la ciudad de Leptis, dice: Eius ciuitatis lingua modò conuersa connubio Numidarum. Iugurth. LXXVII", en BORBÓN, G. de: La conjuracion de Catilina y la guerra de Jugurta por Cayo Salustio Crispo. Madrid, 1772, imprenta de Joaquín Ibarra, pp. 337378).

24. El proyecto fue redactado entre 1774 y 1780 (cf. Pérez BAYER, F.: Por la libertad de la literatura española. Alicante, 1991 [estudio preliminar A. Mestre Sanchís]). De él se conserva una copia en dos volúmenes en la BNE (Mss. 18375-18376), con correcciones manuscritas del propio Pérez Bayer fechadas el 21 de diciembre de 1780.

25. Así se lo indica a Mayans en carta de 10 de marzo de dicho año (MaYans y Siscar, 1977, n. ${ }^{\circ} 222$, pp. 359-360).

26. Juan García, 1918, p. 130.

27. Cf. PÉrez BaYer, F.: De numis hebraeo-samaritanis Dissertatio Isagogica ad tractatum de Phenicum et Graecorum in Hispania Nummis quos incognitos vocant. Valencia, imprenta de Benito Monfort, 1781. De su redacción da cuenta a Mayans en los siguientes términos: "he escrito una Dissertación preliminar de nummis hebraeo-samaritanis en que explico que he recogido originales raríssimas y algunas absolutamente inéditas y de su alfabeto (que no passa de 16 letras y una doble) deduzco los de la lengua o dialecto fenicio y antiguo griego cadmeo, con lo que me introduzco a las dos Dissertaciones que han de seguir, queriendo Dios, y formar el cuerpo de la obra, que pienso que siga un índice geográphico de los pueblos y ciudades montes i ríos de España, deducido de los geógraphos, historiadores, poetas, inscripcionistas, etc., assí griegos como latinos" (MAYANS y SISCAR, 1977, n. ${ }^{\circ} 233$, pp. 374-376). Véase lo dicho supra, n. 10. 
de defender ante las críticas lanzadas contra ella por Olao G. Tyschen ${ }^{28}$. $\mathrm{Al}$ año siguiente, siendo por tanto un hombre de avanzada edad, realizó, a instancias ya de la Real Academia de la Historia, ya de la Corona $^{29}$, el que se considera uno de los principales viajes literarios españoles ${ }^{30}$, que le llevó, desde su patria chica, a las tierras de Andalucía y Portugal. Producto de este viaje fue su Diario del viaje desde Valencia a Andalucía y Portugal, que permaneció inédito hasta finales de la centuria pasada ${ }^{31}$; sobre él volveremos más adelante.

Su dilatada y exitosa carrera culminó con la obtención, en 1783, del muy apetecido cargo de director de la Real Librería, en sustitución del último bibliotecario mayor, Juan de Santander y Zorrilla; desde este cargo, al que ya en 1762 se había dado por hecho iba a acceder de modo inmediato, llevaría a cabo una muy interesante política editorial, si bien en gran

28. Estas críticas fueron publicadas en una carta latina editada con la pertinente traducción al castellano (véase Tyschen, O. G.: Carta latina del señor D. Olao Gerardo Tyschen al Ilmo. Sr. D. Francisco Pérez Bayer con su traducción castellana. Se añade refutación de los argumentos de dicho Señor Bayer en favor de las monedas samaritanas, atribuida al mismo Sr. Tyschen. Madrid, 1786, imprenta de la Viuda de Ibarra). Pérez Bayer las refutó ya en esa misma obra, y, además, publicó dos vindicationes: Pérez BAYER, F.: Numorum hebraeo-samaritanorum vindiciae. Valencia, 1790, imprenta de Benito Monfort (en latín); id.: Legitimidad de las monedas hebreo-samaritanas. Confutación. Valencia, 1793, imprenta de Benito Monfort (en castellano).

29. Síntesis de las diferentes propuestas relativas al patronazgo de este viaje en SALAS Álvarez, J.: "El Viaje arqueológico a Andalucia y Portugal de Francisco Pérez Bayer", Spal, 16, 2007, pp. 10-11.

30. Para los viajes literarios, entendidos en el sentido ilustrado del término, véase Gómez de la Serna, G.: Los viajeros de la Ilustración. Madrid, 1974.

31. Publicado por Mestre Sanchís, Pérez García y Catalá Sanz (eds.), 1998, con los textos de los manuscritos conservados en la BNE (PÉRez BAYER, F.: Diario del viaje desde Valencia a Andalucia y Portugal hecho por Don Francisco Perez Bayer en el año de 1782. Biblioteca Nacional de España, Mss. 5953-5954, copias de 1782; véase Hernando Sobrino, M. ${ }^{a}$ R.: Manuscritos de contenido epigráfico de la Biblioteca Nacional de Madrid (siglos XVIXX). La transmisión de la inscripciones de la Hispania romana y visigoda. Madrid, 2009, pp. 230-237) y los dibujos del Extracto de las inscripciones y otros monumentos antiguos que se encuentran en el manuscrito original que se conserva en la Universidad Literaria de Valencia del Viaje Literario que hizo a Andalucia y Portugal en $1782 \mathrm{el} \mathrm{Illmo.} \mathrm{S}{ }^{\text {or }} D .^{\mathrm{n}}$ Francisco Pérez Bayer, del Consejo, y Cámara de S. M. conservado en la Real Academia de la Historia (RAH 9/5498; ver ABASCAL, J. M. y CEBRIÁN, R.: Manuscritos sobre Antigüedades de la Real Academia de la Historia [Real Academia de la Historia. Publicaciones del Gabinete de Antigüedades. Antiquaria Hispanica 12]. Madrid, 2005, p. 382). 
MARÍA DEL ROSARIO HERNANDO SOBRINO

FRANCISCO PÉREZ BAYER COMO INFORMADOR DE ALEJANDRO JAVIER PANEL

Y APUNTES SOBRE INSCRIPCIONES ROMANAS DE LA PROVINCIA DE SALAMANCA

medida deudora de su antecesor en el cargo $^{32}$; moriría en Valencia apenas abandonada dicha dirección $(1794)^{33}$.

\section{Pérez BAYER y LA EPIGRAFÍA}

Señala Juan García que aunque las biografías por él manejadas para completar la semblanza de Pérez Bayer ${ }^{34}$ indican que este estudió en Salamanca hebreo y griego y, pertrechado con estos conocimientos, antigüedades, lo cierto es que el valenciano debió hacerlo a título personal, pues no consta se matriculase en "lenguas sabias" en la Universidad y, además, en esta no se impartía arqueología: "Pudiera suponerse que algún docto varón le iniciase por entonces en Arqueología y lengua griega, sin profesar estas disciplinas ${ }^{35}$.

¿Fue este docto varón su célebre y eruditísimo paisano Mayans? Bien pudiera, porque la relación epistolar entre ambos personajes data,

32. Tal política comprendió, entre otras, la reedición de la Bibliotheca de Nicolás Antonio (en la imprenta madrileña de la viuda de Joaquín Ibarra, en 1788, con una larga introducción del propio Pérez Bayer), un proyecto largamente ansiado por Mayans y que, como señala Mestre Sanchís en su estudio preliminar al segundo volumen de la correspondencia con Martínez Pingarrón, de la cual se nutre a estos efectos, había sido ideado por el padre Rávago y estaba ya muy adelantado en 1762 (MAYANS y SISCAR, 1988, p. 12). Para su gestión al frente de esta institución véase, además de la introducción de Mestre Sanchís a Mayans y Siscar, G.: Epistolario, IX: Mayans y Martínez Pingarrón, 3: Real Librería y política cultural. Valencia, 1989 [transcripción, estudio preliminar y notas A. Mestre], la obra de García Ejarque, L.: La Real Biblioteca de S. M. y su personal (1712-1836). Madrid, 1997, pp. 163-199.

33. A su muerte, en su patria se le dedicó un sentido panegírico (cf. Sidro Vilarroig, J. F.: In funere Francisci Perezii Bayerii: Oratio ad senat. et acad. Valentinam habita. Valencia, 1797, imprenta de Benito Monfort).

34. Como la de J. Pastor Fuster, véase supra, nota 2.

35. Juan García, 1918, p. 13. No deja de sorprender, a este respecto, que el propio Pérez Bayer, en carta a Mayans de 29 de diciembre de 1745, anote que: "Procedo no sé si diga lentamente o aprissa en el hebraísmo las horas pomeridianas las dos al francés por no perder lo que he podido recoger en mi viage. Espero que en este año 46 sabré el hebreo más que medianamente, digo para entender no sólo la Biblia, sino los libros rabbínicos y leer aquélla sin puntos. De S. Juan en adelante estudiaré por las tardes el griego pues para esse tiempo ya creo avré dexado el francés y me bastará hablar este o otro rato con algún inteligente en este idioma para conservar lo estudiado. El año 1747, si Dios me da vida, tengo ánimo de entregarme todo al griego y por las tardes al hebreo para conservar y aun adelantar algo. Si estas cuentas me salen bien puedo en estos dos años estar bastantemente versado en estas lenguas" (MAYANS y Siscar, 1977, n. ${ }^{\circ}$ 82, pp. 99-100). 
precisamente, de este primer periodo salmantino de Pérez Bayer ${ }^{36}$. Como ya hemos señalado en otro lugar, no fue sino en la figura del sabio de Oliva en la que convergieron, de un modo u otro, todos cuantos en la centuria se interesaron por la epigrafía hispana ${ }^{37}$. El magisterio de Mayans, indiscutible, es expresamente señalado por Pérez Bayer desde las primeras misivas cruzadas entre ambos: "Aprecio infinito los consejos de Vm. en orden al estudio que devo hazer y lecturas que me puedan servir y en especial en lo que toca a los libros de humanidad, ${ }^{38}$.

No obstante lo dicho, no deja de ser cierto que en la escasa correspondencia conservada atribuible a esta primera etapa salmantina (solo 9 cartas entre marzo de 1736 y febrero de 1738) no encontramos ninguna referencia expresa a la Epigrafía. Y son igualmente raras en las misivas siguientes que, por lo común, tratan de intercambio bibliográfico y cuestiones personales, y entre las que abundan las relativas a las expectativas de carrera -solicitudes de recomendación incluidas- de Pérez Bayer.

Sea como fuere, no hay duda de que su experiencia en la materia - si es que no la había generado ya antes, en su tierra natal o en su primera estancia salmantina y al abrigo del influjo de Mayans- se desarrolló en su patria chica, en el periodo en el que trabajó como secretario del arzobispo Andrés Mayoral (recordemos, 1738-1746) ${ }^{39}$. Durante este tiempo, señala

36. La primera carta que consta en el epistolario correspondiente, en latín, fue enviada por Pérez Bayer a Mayans desde Salamanca el 21 de marzo de 1736 (cf. Mayans y SisCAR, 1977, n. ${ }^{\circ}$ 1, pp. 3-4). Obviamente, y aunque carecemos de datos al respecto, es muy posible, habida cuenta de su común origen, que ambos se conociesen antes de la llegada de Pérez Bayer a Salamanca.

37. Hernando Sobrino, M. ${ }^{a}$ R: Alejandro Javier Panel (1699 - 1764) y la epigrafía hispana. Un jesuita francés en el "infierno abreviado" (Scripta Receptoria 11). Bordeaux, 2017 , p. 6.

38. Carta de Pérez Bayer a Mayans de 10 de julio de 1736, también enviada desde Salamanca (cf. MAYANS y SISCAR, 1977, n. ${ }^{\circ} 4$, pp. 6-8). Otro tanto en carta de 19 de febrero de 1744, enviada ya desde Valencia: "y si Vm. me quita mi propensión a las letras, a los doctos y singularmente a Vm., soy lo mismo que un cesto de vendimiar" (Ibid., n. ${ }^{\circ}$ 39, pp. 48-49).

39. Si hemos vaciado bien el correspondiente epistolario, a esta etapa pertenecen las primeras misivas en que Pérez Bayer trata de epigrafía con Mayans. La primera data de 28 de enero de 1744 y, curiosamente, el jesuita Alejandro Javier Panel -de quien trataremos más adelante- es el protagonista de la misma: "Del P. Panel: sitne mei memor incertum, sed adbuc silet altum. Si no mirara, como dicen, que ai Dios imbiara a Vm. un papelón de Marca con unas inscripciones romanas recién sacadas en Aragón (no sé más porque allí se estila no decir a la primera la patria del individuo) una es de letra española antigua" (MaYANS y Siscar, 1977, n. ${ }^{\circ}$ 37, pp. 45-46). La segunda, de 10 de marzo del mismo año, avisa del envío de las "Inscripciones de Aragón y la última de Tortosa, a quienes acompañara yo de buena gana" (Ibid., n. ${ }^{\circ} 42$, pp. 53-55). La tercera, de 24 de febrero de 1745, en 
Y APUNTES SOBRE INSCRIPCIONES ROMANAS DE LA PROVINCIA DE SALAMANCA

Juan García que "tuvo abundantes ocasiones de manifestar sus conocimientos epigráficos, al recorrer la archidiócesis en visita pastoral, interpretando inscripciones difíciles, como aquella latina del castillo de Denia, en que habían fracasado algunos arqueólogos de fama ${ }^{40}$. Se da cuenta aquí, en efecto, de una curiosa anécdota datada en 1744, año en que Pérez Bayer se hizo descolgar de una de las torres del lienzo del muro de la denominada "Villavieja de Denia" para poder leer bien una inscripción cuya lectura se había resistido al cronista Pedro A. Beuter ${ }^{41}$.

Durante este mismo periodo, concretamente en el año de 1745 , hizo un viaje a Francia, con un objetivo triple: restablecer su salud, perfeccionar el hebreo con los rabinos de Avignon y mejorar su francés; no solo satisfizo sus objetivos, sino que, como escribió en septiembre a Mayans, "Accedit que he recogido inscripciones omnino inéditas, medallas y libros buenos. Cuente Vm. entre éstos al ciego Salinas, a Rhua, la Biblia Castellana en dos tomos de Amsterdam, alguno de nuestro Arias y muchos de D. Antonio Augustín, cuio sepulchro he visto y copiado para ver si quadra con el impresso, sus lápidas y por fin todo lo que he podido en este poco tiempo recoger ${ }^{42}$. Sobre el mismo particular vuelve en otras dos cartas, remitidas ya desde Valencia, en octubre del mismo año; en la segunda es algo más explícito: "De inscripciones tengo algunas, que creo passarán de 20, inéditas del todo y otras antigüedades de Tarragona, Tortosa y Barcelona que Vm. avrá visto, las que comunicaré a Vm. gustosíssimo" ${ }^{43}$.

que pregunta a Mayans si tiene "la colección de Inscripciones del deán Martí o copia de ellas" (Ibid., n. ${ }^{\circ}$ 64, pp. 73-74). Para la labor de Manuel Martí en el ámbito de la epigrafía véanse, entre otros, los trabajos de Guglieri VázQuez, J. I.: Manuel Martí, latinista y autor latino, tesis doctoral, Universidad Complutense de Madrid, 1992, y Hernando Sobrino, M. ${ }^{a}$ R.: "Manuel Martí o la legitimación del documento epigráfico", Cuadernos de Filología Clásica. Estudios Latinos, 26, 2, 2006, pp. 193-208.

40. Juan García, 1918, p. 25.

41. Pastor Fuster, 1829, p. 7, quien toma el dato del volumen VII de la España sagrada de Flórez (cf. Flórez, E.: España sagrada. Theatro geographico-historico de la iglesia de España. Origen, divisiones, y limites de todas sus Provincias. Antiguedad, Traslaciones, y estado antiguo de sus Sillas con varias dissertacioes criticas. Tomo VII. De las iglesias sufraganeas antiguas de Toledo: Acci, Arcavica, Basti, Beacia, Bigastro, Castulo, Compluto, Dianio, Elotana, Ilici, Mentesa, Oreto y Osma, segun su estado antiguo. Tomo XIV, Madrid, 1758, oficina de Antonio Marín, pp. 207-208); esta anécdota es también registrada por Hübner en el correspondiente número del Corpus Inscriptionum Latinarum, esto es, en CIL II 3586.

42. Carta escrita desde Marsella el 5 de septiembre de 1745 (MAYANS y Siscar, 1977, n. 77, pp. 93-94).

43. La primera carta es del 20 de octubre, la segunda del 27 del mismo mes (MAYANs Y SISCAR, 1977, n. ${ }^{\circ} 78$, pp. 94-95, y n. ${ }^{\circ} 79$, pp. 95-96). En misiva datada el 15 de junio de 1746, poco antes de marchar a Salamanca, Pérez Bayer escribe a Mayans "Si el Sr. D. Juan 
MARÍA DEL ROSARIO HERNANDO SOBRINO

FRANCISCO PÉREZ BAYER COMO INFORMADOR DE ALEJANDRO JAVIER PANEL

Y APUNTES SOBRE INSCRIPCIONES ROMANAS DE LA PROVINCIA DE SALAMANCA

En suma, la experiencia epigráfica de Pérez Bayer debía de estar ya suficientemente aquilatada cuando se produjo su segunda y conflictiva estancia en Salamanca (1746-1749), a la que creemos es lícito suponer obedezcan los cuidadosos apuntes que el valenciano ejecutó de los epígrafes latinos procedentes de diversas localidades de su provincia, que también envió al mencionado Panel y que serán objeto específico de estudio en un posterior apartado.

Cuando da cuenta a Mayans de su llegada a Toledo para trabajar con Burriel en el marco de la ya citada Comisión de Archivos, Pérez Bayer indica: "De lo demás de inscripciones y antiguallas que aquí se conservan en piedras, edificios y sepulchros, que pueda pertenecer a la era e historia, procuraré no dexar letra y especialmente las hebraicas de la iglesia de Calatrava que antiguamente fue una de las synagogas y otras "44. Y así fue (véase lo dicho supra a propósito de su obra De toletano hebraeorum templo ${ }^{45}$ ) y así sería: especialmente las hebraicas. La importancia de Pérez Bayer en este ámbito fue tal que Casanovas Miró señala que el valenciano constituye el gran referente de los estudios hebreos del s. xviII y que su figura se asocia a todos los hallazgos de epigrafía hebrea de que se tiene constancia, especialmente en el ámbito de la Real Academia de la Historia, durante dicha centuria ${ }^{46}$.

Aunque, como se señaló supra, ya en el curso de su viaje a Francia había estado en Barcelona y copiado inscripciones, es con la posterior estancia de Pérez Bayer en la ciudad condal, en calidad de canónigo

Antonio tuviesse alguna coleccioncilla de inscripciones antiguas de Valencia y del reyno y estuviesse en forma que acá se pudiesse copiar, no me faltaría sugeto de quien valerme para la copia y lo apreciaría mucho" (Ibid. n. ${ }^{\circ} 89$, pp. 111-113).

44. Carta de 5 de octubre de 1750 (MAYANS y SisCar, 1977, n. ${ }^{\circ} 100$, pp. 135-136).

45. De cuya redacción, por supuesto, informa puntualmente Pérez Bayer a Mayans (MAYANS y SisCar, 1977, n. ${ }^{\circ} 104$ y n. ${ }^{\circ} 108$, pp. 139-140 y pp. 144-145, de febrero y diciembre de 1751 , respectivamente).

46. Casanovas Miró, 2005, p. 15. Sobre el mismo particular, Mora, G.: "Los estudios hebraicos en la España ilustrada. Francisco Pérez Bayer y el origen de las lenguas y escrituras antiguas de España", en Domínguez Monedero, A. J. y Mora Rodríguez, G. (eds.): Doctrina a magistro discipulis tradita. Estudios en homenaje al profesor Dr. Luis Garcia Iglesias. Madrid, 2020, pp. 425-454. Con posterioridad, a medida que fue aprendiendo árabe, también las inscripciones arábigas serán objeto de su interés; en 1757, en carta a Mayans enviada desde Roma, ya señala que "En Toledo se conservan aún oi varias inscripciones arábigas que yo he copiado. En Murviedro ai una en las puertas del castillo y también en la Sierra de Espadán. Acaso Dios nos dará modo de interpretarlas" (MAYANS y SISCAR, 1977, n. ${ }^{\circ} 126$, pp. 195-198). Años después, el interés por la epigrafía árabe seguía vivo, tal y como se desprende de dos cartas que le remitió Juan Antonio Mayans, hermano de Gregorio Mayans, en noviembre de 1781, a propósito de una inscripción de Tortosa (Ibid., n. 265 y n. ${ }^{\circ} 266$, p. 409 y pp. 409-410, respectivamente). 
MARÍA DEL ROSARIO HERNANDO SOBRINO

FRANCISCO PÉREZ BAYER COMO INFORMADOR DE ALEJANDRO JAVIER PANEL

Y APUNTES SOBRE INSCRIPCIONES ROMANAS DE LA PROVINCIA DE SALAMANCA

(1752-1754), con la que debemos relacionar el grueso de los apuntes relativos a epígrafes de Barcelona, Mataró y Tarragona (los de esta última ciudad en realidad correspondientes a piezas conservadas en Barcelona, pero procedentes de la antigua Tarraco $)^{47}$; de ello da cuenta el propio hebraísta en carta a Mayans fechada en 24 de abril de $1753^{48}$. Estos apuntes, que Pérez Bayer compartió con Panel, y obviamente también con Finestres (aunque no todos) ${ }^{49}$, escaparon al control de Hübner, pero no solo han sido ya reconocidos -aunque vinculados a diferentes manuscritos-, sino también aprovechados y bien valorados por los editores de IRC IV (Barcino) y del $C I L \mathrm{II}^{2} / 14$.

También desde Barcelona sigue el hebraísta trabajando en el tema de las "escrituras desconocidas" que, como ya se indicó ${ }^{50}$, constituía una de sus materias favoritas. Con ella debe relacionarse una de las múltiples peticiones elevadas a Mayans cuando ya estaba preparando su marcha a Italia ${ }^{51}$. También Pérez Bayer estaba interesado, como no podía ser de otra manera, por la epigrafía paleohispánica.

47. Con esta misma estancia relaciona Gimeno los apuntes de epigrafía barcelonesa (cf. Gimeno Pascual, H.: "Los estudios epigráficos en España en el siglo xviii", en AlmagroGorbea, M. y Maier Allende, J. (eds.): De Pompeya al nuevo mundo. La Corona española y la Arqueología en el siglo XVIII (Real Academia de la Historia. Publicaciones del Gabinete Antigüedades, Antiquaria Hispanica, 23). Madrid, 2012, p. 147, n. 38); sobre este tema volveremos infra.

48. "Aquí con los cumplidos y cuidados de mi establecimiento lo he ido procrastinando, según mi genio naturalmente perezoso para tomar la pluma, pero aviendo logrado esta semana santa el conocimiento del Sr. Dn. Joseph Finestres y logrado de su docta conversación, rara vez de las muchas que hemos concurrido se ha dexado de hacer mención de Vm., como que su presencia sería para este cavallero y para mí el complemento de el gusto y mutua satisfacción. Razón tiene Vm. para estimarle tanto y hacer el concepto que merecen su doctrina, su candor y demás bellas qualidades. Ha visto mis tales quales trabaxos y hemos cotexado nuestras inscripciones y antes de passar a Gerona (donde hace ánimo de ir a visitar a un hermano canónigo) hemos de visitar una por una las inscripciones de esta ciudad" (MAYANS y Siscar, 1977, n. ${ }^{\circ} 112$, pp. 148-149).

49. Véase Casanovas, I. y Batllori, M.: Josep Finestres. Epistolari, suplement. Barcelona, 1969, carta 1479, p. 203. Finestres los emplearía para la elaboración de su inestimable Sylloge (cf. FINESTRES, J.: Sylloge inscriptionum romanarum, quae in principatu Catalauniae vel extant vel aliquando extiterunt. Cervera, 1762, imprenta de Ibarra), que debió mucho al aliento del infatigable Mayans, quien años después solicitaría a Pérez Bayer animase a Lázaro Dou para reeditar la obra (MAYANS y SISCAR, 1977, n. ${ }^{\circ} 246$, p. 391).

50. Véase supra, nota 10. Para su importancia en el ámbito de la epigrafía fenicia véase la más reciente síntesis de VIDAL, J.: "Francisco Pérez Bayer y los estudios de epigrafía fenicia", Aula Orientalis, 31, 2, 2013, pp. 323-332, con la bibliografía previa que hace al caso.

51. "Dígame Vm. si alguna observación tuviesse hecha en orden a las antiguas letras españolas y si sabe de otro algún monumento de esta classe fuera de los dos que traen 
Su interés por la epigrafía se mantuvo vivo en el transcurso de su viaje con destino a Roma, no en vano informó a Mayans de que durante su estancia en Turín cotejó, una a una, todas las inscripciones del claustro inferior de su Universidad, que ya habían sido registradas por Scipione Maffei ${ }^{22}$ : «enmendé lo que no encontré fielmente copiado y añadí unas veinte inscripciones halladas posteriormente a la edición de aquéllas," ${ }^{53}$; en la misma misiva le indica que, en su avance, iba realizando una colección de inscripciones inéditas. No obstante, es cierto que en las epístolas conservadas de este periodo son escasas las noticias de carácter epigráfico, siempre eclipsadas por las bibliográficas; apenas hemos podido espigar una en la que Pérez Bayer narra a Mayans la localización en Tíbur de un "fragmento de inscripción antigua en que se halla claramente MVNICIPIVM SAETABIS HISP. CIT. ${ }^{54}$. Mayans, perfecto conocedor de la

\footnotetext{
Ximeno, Velázquez y las monedas y si de este género tuviesse Vm. alguna clara (porque las dudosas no sirven sino de quebrarse uno la cabeza) y rara, esto es que ni Velázquez ni Lastanosa la traigan, estimaría a Vm. mucho me embiasse su dibujo. Tengo varias conbinaciones hechas sobre esta parte de antiquaria y qué quiere $\mathrm{Vm}$. que diga, no decaigo aun de la esperanza de adelantar algo en esta materia" (MAYANS y SISCAR, 1977, n. ${ }^{\circ}$ 114, pp. 150-152, carta de 23 de abril de 1754). La respuesta de Mayans es clara: "Mucho me holgara que Vm. fuesse el descubridor de la letura de las medallas desconocidas de España. De la inscripción de Murviedro yo soi testigo. No sé que aya parecido otra además de las que Vm. ya tiene noticia. Me falta el tiempo para meditar sobre este descubrimiento, que tengo por mui dificultoso, por ser desconocida la lengua i aun los nombres propios, por averse grecizado o latinizado, que es lo mismo que corrompido" (Ibid., n. ${ }^{\circ} 115$, pp. 152-153). Se alude aquí a las obras, en orden cronológico, de: Lastanosa, V. J.: Museo de las medallas desconocidas españolas. Huesca, 1645, imprenta de Juan Nogues; Jimeno, V.: Escritores del reyno de Valencia, chronologicamente ordenados desde el año de MCCXXXVIII de la Christiana conquista de la misma Ciudad, hasta el de MDCCXLVII. Valencia, 1747, imprenta de José E. Dolz, vol. I, p. 111, y VelázQuez De Velasco, L. J.: Ensayo sobre los alphabetos de las letras desconocidas que se encuentran en las mas antiguas Medallas, y Monumentos de España. Madrid, 1752, imprenta de Antonio Sanz. Las dos inscripciones ibéricas a que se alude en esta correspondencia proceden de la localidad turolense de La Iglesuela del Cid y de la valenciana Sagunto - conocida como Murviedro antes de su cambio de nombre- y corresponden a MLH III E.8.1 y F.11.11, respectivamente (cf. UNTERMANN, J.: Monumenta Linguarum Hispanicarum. Band III: Die iberischen Inschriften aus Spanien. 2. Die Inschriften. Wiesbaden, 1990).

52. MAFFeI, S.: Museum veronense hoc est antiquarum inscriptionum atque anaglyphorum collectio cui Taurinensis adiungitur et Vindobonensis. Accedunt monumenta id genus plurima nondum vulgata, et ubicumque collecta. Verona, 1749. Para la elaboración de esta obra el conocido epigrafista y marqués de Verona contó con la activa colaboración del deán Martí.

53. Carta enviada desde Milán, a 21 de julio de 1754 (Mayans y Siscar, 1977, n. 116, pp. 153-156).

54. Misiva remitida desde Roma, a 2 de marzo de 1756 (Mayans y Siscar, 1977, n. ${ }^{\circ}$ 121, pp. 170-181). El epígrafe de referencia no es otro que CIL XIV 3795, de Tibur, que
} 
Y APUNTES SOBRE INSCRIPCIONES ROMANAS DE LA PROVINCIA DE SALAMANCA

bibliografía epigráfica hispana -como pone de relieve su impresionante carta a Walch ${ }^{55}$-, le indica en su respuesta que la inscripción se encontraba ya recogida en el repertorio de Ludovico A. Muratori ${ }^{56}$.

Su etapa de catalogación en El Escorial es obvio que, tal y como puede deducirse de la pertinente correspondencia con Mayans, no resultaba las más apropiada para el desarrollo de inspecciones de carácter epigráfico. Pese a ello, cuando la ocasión lo permitía -o expresamente así se le solicitaba $^{57}$-, Pérez Bayer no olvidaba esta faceta; así podemos deducirlo de una visita que cursó en 1763 a Sepúlveda, alentada por Carlos III, a quien habían llegado dos "casquetes" de oro procedentes de aquella localidad; informado el monarca por el corregidor de la misma de que, junto al lugar del hallazgo de los casquetes, se había descubierto un edificio subterráneo de fábrica romana y una inscripción, también romana, envió a Pérez Bayer en misión de reconocimiento. De tal misión se dedujo que no había tales, no obstante, en su carta a Mayans indicaba que:

en Sepúlveda (cuya situación puede mui bien competir con la de la patria de Ulysses, tal es de áspera y enriscada) recogí quantas memorias pude romanas. Una queda sola entera y quatro fragmentos y en ellas se conservan los nombres de las familias Valeria, Aurelia, Coruncania y el de O. Capitón. Dudo que haya de ellas memoria en Grutero ${ }^{58}$ y creo que nadie las haya publicado asta ahora ${ }^{59}$.

constituye, en efecto, uno de los testimonios en virtud del cual se conoce el rango municipal de la antigua civitas identificada con la actual Játiva (véase, entre otros, la introducción de Corell a IRST ${ }^{2}$ (CORELl I VICENT, J.: Inscripcions romanes del País Valencià III. (Saetabis $i$ el seu territori). Valencia, 2006, pp. 20-21).

55. La larguísima carta fue editada por L. Abad Casal y J. M. Abascal, quienes ya ponen de relieve la erudición del de Oliva (véase MAYANS Y SISCAR, G.: Introductio ad veterum inscriptionum historiam literariam (Real Academia de la Historia. Publicaciones del Gabinete de Antigüedades. Estudios 4). Madrid, 1999; introducción de los editores en pp. 13-17).

56. Mayans y Siscar, 1977, n. ${ }^{\circ} 122$, pp. 182-183. Muratori, L. A.: Novus thesaurus veterum inscriptionum in praecipuis earundem collectionibus hactenus praetermissarum. Milano, 1739-1742, 4 vols.

57. Como la explicación de algunas inscripciones recién halladas en Pompeya, que le costó un cierto disgusto: "También he tenido que hacer una apología contra un señor de gran doctrina y autoridad de Nápoles el qual impugnó la explicación que hize de tres o quatro hallazgos de inscripciones y otras antigüedades nuevamente descubiertas en Pompei, las que tuvo S.M. la benignidad de decir que se me enseñassen y huve de decir casi ex tempore lo que me ocurría, y luego salió el antirrhético bastantemente fuerte" (carta de 28 de abril de 1764, MaYans y Siscar, 1977, n. ${ }^{\circ}$ 155, pp. 254-258).

58. GRUTERO, J.: Inscriptiones antiquae totius orbis Romani in corpus absolutissimi redactae. Heidelberg, 1603.

59. Carta de 27 de junio de 1763 (Mayans y Siscar, 1977, n. ${ }^{\circ} 149$, pp. 238-242). 
Si Pérez Bayer tomó los oportunos apuntes, huelga decir que estos se perdieron, pues no parece se los llegase a proporcionar a ninguno de sus corresponsales habituales, Panel entre ellos. El hecho es muy de lamentar porque el conjunto de epigrafía de Sepúlveda es, además de ralo (diez inscripciones en $E R S g)^{60}$, muy pobre en contenidos; de esos diez epígrafes, en efecto, solo tres se encuentran ya registrados en el CIL II $^{61}$, permaneciendo los restantes inéditos hasta en el último decenio del siglo xx e, incluso, hasta la propia fecha de edición del citado corpus (2005).

Con esta preparación previa, abordaría Pérez Bayer una de las tareas que, sin duda, mayor nombre le dieron en el ámbito de la epigrafía: la condena pública y oficial de la serie de inscripciones supuestamente halladas en la Alcazaba granadina en el curso de las excavaciones realizadas en el lugar -entre los años 1754 y 1763- por el "pícaro" Juan de Flores y Oddouz $^{62}$. Pérez Bayer comenzó a estudiar estas inscripciones en enero de 1765, tal y como se deduce de una carta que envió a Mayans en febrero de dicho año $0^{63}$; en ella anota que desde el mes pasado está trabajando, por encargo, en "un assumto que aunque nos es común a todos los españoles toca mui particularmente a Vm.». No desvela el tal asunto a Mayans, apelando a su paciencia $(" \mathrm{Vm}$. por ahora no sea curioso en querer saber el assumto. Es regular que a su tiempo lo sepa Vm. todo de golpe y lea lo que se ha hecho que son cerca de 50 pliegos"); el de Oliva, no obstante, debió averiguar de qué se trataba ya que, en su siguiente misiva, Pérez Bayer así

60. Santos Yanguas, J., Hoces de la Guardia Bermejo, Á. L. y del Hoyo, J.: Epigrafía romana de Segovia y su provincia. Segovia, 2005, n. ${ }^{\circ}$ 156-165. Interesará conocer que los tales casquetes se hallaron en un lugar llamado la Adrada, según Pérez Bayer, ¿se trata de la Cueva Labrada de que dan cuenta estos investigadores?

61. CIL II 3089 (=ERSg 159), tomada de Ludovico A. Muratori, CIL II 2768 (=ERSg 162), conocida a través de Aureliano Fernández Guerra, y CIL II $2764 a$ (=ERSg 165), vinculada con Ambrosio de Morales.

62. Tomamos prestado el epíteto de la obra de Orfila, M. et alii: La Granada afalsificada: el pícaro Juan de Flores. Granada, 2012. No nos detendremos en los detalles y pormenores del engaño, bien analizado en esta obra y en otras previas, en especial en Godor Alcántara, J.: Historia crítica de los falsos Cronicones. Madrid, 1868 [reed. 1981], pp. 317325; Vegué y Goldoni, A.: "Para la historia de la arqueología en España. El canónigo Pérez Bayer y los Nuevos Monumentos de Granada", Anuario del Cuerpo de Facultativos de Archiveros, Bibliotecarios y Arqueólogos, 2, 1934, pp. 25-51; Álvarez Barrientos, J. y Mora Rodríguez, G.: "El final de una tradición. Las falsificaciones granadinas del siglo XVIII", Revista de Dialectología y Tradiciones populares, 40, 1985, pp. 163-189; Sotomayor, M.: "Excavaciones arqueológicas en la Alcazaba de Granada (1754-1763)", en Miscelánea Augusto Segovia, Granada, 1986, pp. 243-283; id.: Cultura y picaresca en la Granada de la Ilustración. D. Juan de Flores y Oddouz. Granada, 1988, y Caro Baroja, J.: Las falsificaciones de la Historia. Madrid, 1991 [reed. 1992], pp. 143-150.

63. MAYANS y SisCar, 1977, n. $^{\circ} 158$, pp. 261-262. 
MARÍA DEL ROSARIO HERNANDO SOBRINO

FRANCISCO PÉREZ BAYER COMO INFORMADOR DE ALEJANDRO JAVIER PANEL

Y APUNTES SOBRE INSCRIPCIONES ROMANAS DE LA PROVINCIA DE SALAMANCA

lo admite y, además, pasa a dar detallada cuenta de sus apuntamientos al respecto y del método que ha seguido en ellos para desacreditar los escritos de Cristóbal Medina Conde ${ }^{64}$. Por su innegable interés, reproducimos aquí sus palabras:

Los nuevos monumentos, assí sagrados o eclesiásticos como profanos, son asta ahora 66. De éstos, digo de los profanos, hai cinco incontestablemente verdaderos (no tema Vm. que también aquí ha avido algún enemigo hombre que sobre el trigo ahechado y puro ha sobresembrado zizaña); los demás si no son falsos de toda falsedad yo no he visto cosa más parecida a ello en mi vida, digo los demás sagrados y profanos. Ahora, pues, yo entresaco los 5 verdaderos del resto, quiero decir el grano de la paja, pruebo su legitimidad por sus nociones, impugno la falsa falsíssima lección, versión y explicación que se les ha dado y creo que hago demonstración de que ni el autor de las 4 cartas, ni sus fieles aliados Barbán de Castro, Viana, Flores, (D. Juan) Santos de Urbina, ni otros los han entendido poco ni mucho los tales cinco monumentos y que en este estudio están mui a los principios. Hecho esto por vía de exordio, hago mi proposición que es querer confrontar los characteres de la verdad hallados en las 5 inscripciones con los que se hallan en las demás que por ahora llamo dudosas, las que examino (las profanas, digo, porque de las sagradas no hablo sino de passo reservándome para tratar de ellas en caso necessario) una a una en los puntos que diré después, porque antes de llegar al cotejo hago varias salvas y una de ellas es que yo no me meto por ahora (como si no fuera causa común e inseparable) a tratar de los antiguos descubrimientos granatenses Turpiano e Ilipulitano sí solo de los monumentos nuevamente descubiertos como si nada huviera de los antiguos. Digo lo que puedo de las causas que me han movido y obligado a escrivir mis apuntamientos y, antes de comenzar el cotejo de las nociones de unos y otros monumentos, hago dos reflexiones comunes a todos, una de las quales es fundada en Palaeografía en que mi juicio demuestro que todos los nuevos monumentos son escritos de una mano con aver de uno a otros muchos siglos. Discurra Vm. probado esto si queda más que probar! Passo luego al cotejo y lo hago de las 5 inscripciones con las 40 que hai profanas en los puntos siguientes.

1. En la calidad de las piedras.

2. En el tamaño (que es mui del caso para demostrar si fue o no fácil supplantarlos).

64. Fue uno de los más estrechos colaboradores de Juan de Flores y desplegó una intensa actividad literaria en defensa de las antigüedades de la Alcazaba; es el autor de las cuatro cartas que menciona Pérez Bayer en su misiva. 
3. En el charácter de su escritura y si ésta corresponde a los tiempos en que suenan escritos los monumentos de que se duda.

4. En la orthographía y falta de ella.

5. En la propiedad latina.

6. En la conformidad o desconformidad con otros documentos ciertos y canonizados por tales, en la concissión, en la perspicuidad del estilo y generalmente en el estilo.

7. En la harmonía de los ciertos con la historia, chronología y geographía y la dissonancia de los dudosos. Varios reparos sobre estos tres puntos.

8. Dejo de hacer el cotejo de los lugares donde se encontraron los unos y los otros porque para esto es menester más conocimiento topográfico del sitio de la Alcazaba que el que yo tengo.

9. Últimamente pongo un appéndice o Dissertación acerca del nombre de Granada y del tiempo en que comenzó a llamarse assí la ciudad de este nombre, y creo que si lo que digo no es cierto a lo menos es incomparablemente más verosímil que quanto se ha dicho hasta aquí. Lo que resulta de cada ramo o de cada particular cotejo todo conspira a corroborar el reparo transcendental de que todos son de una mano, y en mi juicio, cotejadas las cinco con las demás inscripciones, sucede a éstas lo que sucedió a Dagón y a los ídolos puestos delante de la Arca del Señor ${ }^{65}$.

Los epígrafes de la Alcazaba granadina hicieron correr casi tantos ríos de tinta como previamente habían desencadenado los célebres plomos del Sacromonte, pero no llegaron tan lejos como estos; dado que el engaño fue pronto descubierto gracias a la delación de uno de los colaboradores de Juan de Flores, el pintor Lorenzo Marín, en 1774 se inició un proceso que, jalonado por una Real Orden en 1765 -en virtud de la que se prohibió toda publicación sobre los hallazgos-, culminó con una sentencia condenatoria firme en 1777 .

La mayor gloria en esta condena se la llevó, en efecto, Pérez Bayer ${ }^{66}$, aunque como bien señala Mayans en carta a Asensio Sales, con una cierta amargura, no fue el único que había trabajado en ello:

65. MAYANS y SISCAR, 1977, n. ${ }^{\circ} 159$, pp. 262-265. Las cartas n. ${ }^{\circ} 160,161,162,163,164$, etc., todas de 1765 , continúan tratando el mismo tema.

66. Para el peso de la opinión y testimonio de Pérez Bayer en esta condena véase la Razón del juicio (Razón del juicio seguido en la ciudad de Granada ante los ilustrisimo señores Don Manuel Doz, presidente de su Real Chancilleria; Don Pedro Antonio Barroeta y Angel, Arzobispo de que fue de esta diocesis y Don Antonio Jorge Galvan, actual sucesor en la Mitra, todos del Consejo de su Majestad: contra varios falsificadores de escrituras públicas, monumentos sagrados, y profanos, caracteres, tradiciones, reliquias, y libros de 
MARÍA DEL ROSARIO HERNANDO SOBRINO

FRANCISCO PÉREZ BAYER COMO INFORMADOR DE ALEJANDRO JAVIER PANEL

Y APUNTES SOBRE INSCRIPCIONES ROMANAS DE LA PROVINCIA DE SALAMANCA

Ya tendrá V. S. Ilma. noticia del decreto real contra los que han escrito en defensa de las láminas de Granada i los que escrivían. Tres valencianos hemos sido los que hemos peleado contra ellas con mayor vigor: D. Juan Bautista Pérez que empezó a combatirlas, yo que, por averlas impugnado, fui perseguido i D. Francisco Pérez que ha triunfado de sus defensores. Gracias a Dios que ha prevalecido la verdad a tan abominables ficciones ${ }^{67}$.

Aunque alineado en este caso con la opinión de Mayans y del padre Martín Sarmiento, entre otros, no es menos cierto que a Pérez Bayer se le ha reprochado su "pasividad" ante otros textos, también sospechosos de falsedad, cuya refutación o abierta denuncia hubiesen podido entorpecer su carrera ${ }^{68}$; a buen entendedor... En cualquier caso, lo cierto es que la pronta condena de las nuevas falsificaciones granadinas evitó que sus textos se integraran en el corpus hispano.

Su interés por las lenguas paleohispánicas, del que ya hemos dado cuenta, de algún modo se revitaliza tras la redacción de su obra Del alfabeto y lengua de los fenices $y$ de sus colonias ${ }^{69}$, de suerte que encontramos a Pérez Bayer dispuesto a comprobar algunas lecturas sobre el terreno:

Quiero assimismo passar a la iglesuela a Nuestra Señora del Cid y ver aquella inscripción celtibérica y traérmela en plancha pues las copias no sirven. Ahora ocho años en dos horas que estuve de tránsito en Murviedro descubrí otra celtibérica de que nadie creo tenga noticia (porque no es la que han publicado tantos). Copiéla como pude y tengo gran miedo de que la muden de sitio o se pierda, porque no es lápida grande. Quiero recoger todo esto y hacer mis esfuerzos para su interpretación. De otra también celtibérica de Cazlona, larga de siete líneas, creo haverla logrado y no me queda escrúpulo porque el alfabeto

supuesta antigüedad. Madrid, 1781, imprenta de Joaquín Ibarra, passim pero, en particular, pp. 202-207) y las palabras que, sobre esta obra, emite Hübner (CIL II, p. XXIII, n. ${ }^{\circ}$ 75). En septiembre de 1780 Pérez Bayer se lamentaba a Mayans "Huviera ya concluido de dar la última mano al original de mi primer tomo para embiarlo a éssa a imprimir, si no me huvieran interrumpido con la revisión de ciertos apuntamientos que en 1765 escribí en Toledo contra las láminas de Granada, porque va a imprimirse la sentencia contra los falsarios a sus expensas. A la verdad es justo se vindique el honor de la nación y no nos tengan los extrangeros por más bárbaros de lo que somos" (MAYANS y SISCAR, 1977, n. ${ }^{\circ} 260$, pp. 404-405).

67. MaYans y Siscar, G.: Epistolario, V: Escritos económicos. Valencia, 1976 [estudio preliminar de E. Lluch, selección, transcripción y notas de A. Mestre Sanchís], n. ${ }^{\circ}$ 32, pp. 53-54, de 8 de julio de 1765.

68. Esta es la opinión de Gimeno Pascual, 2003, pp. 193-197, quien abunda en el concepto, perfectamente comprensible, que de Pérez Bayer tenía el íntegro Mayans.

69. Véase supra, notas 23 y 50. 
le hallo acomodado a las antiguas inscripciones griegas y monedas, y el sentido que resulta es perfecto y acomodado a la syntaxi griega ${ }^{70}$.

No obstante, su mayor logro en materia epigráfica, por su difusión y repercusión, radica en su ya mencionado Diario del viaje desde Valencia a Andalucía y Portugal, realizado en $1782^{71}$, que fue ya halagado por Hübner: "eius itineris reliquit descriptionem plenam et accuratam" ${ }^{72}$. Este Diario registra una nutrida colección de inscripciones, muchas de las cuales eran inéditas en su momento, todas ellas, obvio, producto de la autopsia directa realizada por Pérez Bayer, quien indicó a Juan Antonio Mayans:

Vamos a mi viage. De las inscripciones fenicias que citan Franco y Valera ninguna he hallado después de las más exquisitas diligencias. En Alcalá del Río (que es Osset o Ilipa) hallé una, encontré, digo, una que no buscaba. Es mui preciosa. Griegas dos o tres de los siglos bajos. Inscripciones latinas he visto y copiado en su proprio carácter algunas 1.200 o más: muchíssimas, todas, que hacen maravillosamente a nuestra historia y disciplina eclesiástica del siglo VII. Lo que hai notable de templos, teatros, circos, estatuas, capiteles, adornos, etc., viene todo copiado $^{73}$.

Que Pérez Bayer tenía intención de proseguir con su viaje de inspección es extremo que también podemos deducir de su comunicación epistolar con Juan Antonio Mayans:

Todos los amigos me retrahen del viage, sino Vm., cuio dictamen (que Vm. por favorecerme) funda en la utilidad y yo en mi honor y en estar comprometido con el público, prevalecerá a pesar de mis años cumplidos y de otras razones que yo estimo que non cadunt in virum constantem. Si no me hallasse, como gracias a Dios me hallo, reparado 360).

70. Carta a Mayans de 10 de marzo de 1775 (MaYAns y SisCar, 1977, n. ${ }^{\circ} 222$, pp. 359-

71. Una primera referencia a la idea de este viaje, según Mestre Sanchís, en carta de Pérez Bayer a Mayans de mayo de 1781: «Pienso para el segundo tomo ver y hollar con mis pies la carta de la Bastetania, desde Virgi a Carteia, el estrecho, la costa de océano asta Sylves, Cuneo y Promontorio Sacro, y luego una y otra ribera del Betis desde el mar asta Sevilla. Todo fue habitado por Phenices. Vendrán conmigo un buen dibujante y un diestro matemático para sacar copias, levantar planos, observar grados y resistencias, etc." (MAYANs Y SISCAR, 1977, n. $^{\circ} 263$, p. 407, n. 352). Dado que Mayans murió en 1781, no podemos seguir las impresiones de este proyecto a través del epistolario cruzado entre ambos, aunque Pérez Bayer siguió en comunicación con Juan Antonio Mayans y es posible espigar algún dato sobre el particular en las cartas cruzadas en abril y mayo de 1782 (cf. Ibid., n. ${ }^{\circ} 267-$ 269, pp. 410-413).

72. CIL II, p. XXIII, n. ${ }^{\circ} 75$.

73. MAYANS y SiscaR, 1977 , n. ${ }^{\circ} 270$, pp. 413-414, carta de 24 de diciembre de 1782. 
MARÍA DEL ROSARIO HERNANDO SOBRINO

FRANCISCO PÉREZ BAYER COMO INFORMADOR DE ALEJANDRO JAVIER PANEL

Y APUNTES SOBRE INSCRIPCIONES ROMANAS DE LA PROVINCIA DE SALAMANCA

de mi fluxión y otras zarandajas, tampoco sería razón exponerme. Iacta est alea. Pienso el 3 ó 4 de junio salir de aquí, tratar a los sabios de Coimbra, recoger las antiguallas de Braga y las nuestras de Alcántara, Ventas de Capara, León, Osma, Coruña del Conde, Cascante, Loharre, Agreda, etc. Si no fuera por la precissión de hallarme aí el próximo otoño, a lo que Vm. discurrirá, huviera sido mi segunda salida no menos famosa que la de D. Quixote ${ }^{74}$.

Como sabemos, el proyecto no pasó de ser tal, hecho que, sin duda, nos ha privado de una fuente de información preciosa.

Volviendo al Diario, y como ya se señaló en otro lugar, al no tratarse de un corpus de inscripciones propiamente dicho, sino del relato de un viaje, en la presentación de las inscripciones se echan en falta aspectos tales como la indicación de la bibliografía precedente o las variantes de lectura; sin embargo, ello no resta ni un ápice de valor al documento. En efecto, en sus copias no se descuidan, además de la correcta transcripción del texto (distribución interlineal, puntuación, lagunas, etc.), los datos que se consideran imprescindibles en la correcta edición de un epígrafe: lugar de hallazgo y de conservación y características físicas ${ }^{75}$.

Como se ha adelantado, el Diario no fue objeto de una edición íntegra sino hasta fechas relativamente recientes (1998); no obstante, ya se había editado parcialmente ${ }^{76}$ y sobre el mismo, y sobre la labor epigráfica de su autor, habían aparecido publicaciones y análisis puntuales, que cubrían de modo bastante irregular los territorios visitados por el valenciano. El más antiguo trabajo se debe a Leite de Vasconcellos, que estudió su viaje por Portugal $^{77}$-como años después haría el hispanista francés Piwnik ${ }^{78}$-; al de Vasconcellos seguiría en el tiempo un artículo de Mateu y Llopis dedicado a dar cuenta de los estudios de epigrafía ibérica y hebrea de Pérez Bayer en Sagunto ${ }^{79}$; a este, otro de Rubio Paredes en el que se analiza el viaje en

74. MAYANS y SiSCaR, 1977 , n. ${ }^{\circ} 273$, pp. 416-417, carta de 30 de mayo de 1783.

75. Hernando SOBRINo, 2017, p. 60.

76. En diversos fascículos de los números 3-4 de la revista La Alhambra (1900-1901).

77. Leite de Vasconcellos, J.: "Viagem de Pérez Bayer em Portugal, em 1782", O Arqueólogo Portugués, 24, 1920, pp. 108-176.

78. PIwnIK, M.-H.: "Les deux voyages de F. Pérez Bayer au Portugal. 1782, 1783", Revista de Historia Moderna, 3, 1981, pp. 261-317. Este autor considera los viajes de Pérez Bayer los más desinteresados de cuantos se efectuaron por aquellas fechas y señala que, por lo mismo, sus testimonios son más ricos y objetivos (Ibid., p. 265).

79. Mateu y Llopis, F.: "Pérez Bayer i les inscripcions ibèriques i hebraiques de Molvedre", Boletín de la Sociedad Castellonense de Cultura, 12, 1931, pp. 248-257. 
tierras de Cartagena ${ }^{80}$, y a este, finalmente, otro dedicado por Álvarez de Morales a su periplo por tierras andaluzas ${ }^{81}$.

La ya referida edición íntegra del Diario publicada en 1998 por los profesores Mestre Sanchís, Pérez García y Catalá Sanz, absolutamente necesaria, no agotó los estudios sobre este viaje. Muy próximo en el tiempo a esta edición, Mas Galvañ y Abascal dedicaron un estudio específico y detallado al periplo de Pérez Bayer por Valencia y Murcia ${ }^{82}$ y, en fechas recientes, Salas Álvarez ha hecho otro tanto centrándose en tierras andaluzas ${ }^{83}$.

Como bien indica Abascal en el trabajo recién mencionado, pocas sorpresas aguardan al epigrafista en el Diario de Pérez Bayer que, como hemos visto, fue oportunamente vaciado por Hübner para la confección del CIL II; no obstante, señala con acierto que "el manuscrito guarda un tesoro no siempre convenientemente empleado, que es el referido a la procedencia exacta de los epígrafes o a su lugar de conservación en 1782. Pérez Bayer describió con precisión el lugar que ocupaban las inscripciones que describía, a veces con una meticulosidad que rebasa incluso el empeño de Lumiares, de cuyos apuntes topográficos, como hemos dicho, se guía" ${ }^{84}$.

Bien pudimos nosotros comprobar este extremo cuando hubimos de catalogar los manuscritos de contenido epigráfico de la BNE y, en consecuencia, abordar los correspondientes a los dos volúmenes de este Diario (Mss. 5953 y 5954). Descubrimos entonces, en efecto, que, aunque escasas, se encontraban en estos manuscritos inscripciones que habían escapado al control de Hübner y habían permanecido inéditas hasta los años 90

80. Rubio Paredes, J. M.: "Cartagena en el "Viaje literario" de Pérez Bayer", Murgetana, 81, 1990, pp. 91-104.

81. Álvarez de Morales, A.: "Pérez Bayer y su viaje a Andalucía en 1782", en Actas del II Coloquio de Historia de Andalucía Moderna. Córdoba, 1983, pp. 185-197.

82. Mas Galvañ, C. y Abascal, J. M.: "El viaje literario de Francisco Pérez Bayer por Valencia y Murcia (1782)", Saitabi, 48, 1998, pp. 79-111.

83. Véase nota 29.

84. Mas Galvañ y Abascal, 1998, p. 102. 
MARÍA DEL ROSARIO HERNANDO SOBRINO

FRANCISCO PÉREZ BAYER COMO INFORMADOR DE ALEJANDRO JAVIER PANEL

Y APUNTES SOBRE INSCRIPCIONES ROMANAS DE LA PROVINCIA DE SALAMANCA

de la pasada centuria ${ }^{85}$ e incluso otras, menores $^{86}$ o mal entendidas $^{87}$, que aún podían ser individualizadas e integradas en el corpus hispano.

En suma, a pesar de sus defectos y lagunas, el trabajo epigráfico de Pérez Bayer ha sido generalmente alabado por la comunidad científica, que ha sabido sacar buen provecho de su rica información.

Al frente ya de la Real Librería, y acometiendo la catalogación de sus fondos, el valenciano seguirá dando muestra de su interés por la Epigrafía al encontrar según qué obras:

Había visto citado el libro de inscripciones antiguas de España que escribió D. Francisco Llansol de Romaní, y Vm. tendrá de él mucha noticia. Deseaba muchíssimo verle y hoi, por una casualidad, me ha venido a las manos el mismo original, aumentado por el Dr. Gaspar Escolano, entre los manuscritos de la real biblioteca, cuio índice estoi formando, porque no le hai asta ahora. Este libro fue primero del Dr. Gaspar Escolano, después de Mn. Gerónimo Martínez de la Vega, vicario que fue del Hospital General de Valencia (de quien hai una poesía en la Expulsión de los moriscos de Valencia de Gaspar Aguilar), después fue de D. Hipólyto Samper, después de D. Andrés González de Barcia de cuia librería passó a la real biblioteca. Hai sin duda en él muchas cosas buenas y especialmente muchíssimas inscripciones que ya hoi no existen y están las más copiadas con exactitud ${ }^{88}$.

Citamos aquí este dato porque la obra de Llançol de Romaní de cuyo hallazgo se da cuenta (De los ríos de Hispania) fue también registrada por Mayans en su carta a Walch y, como señalan los editores de esta larga misiva, tal obra no se conoce más que por referencias indirectas ${ }^{89}$. De hecho, en su respuesta a la carta de Pérez Bayer, Juan Antonio Mayans, quien

85. Así HEp 5, 1995, 32 (dependiente de Corell i Vicent, J. y Gómez i Font, X.: "Inscripciones romanas del país Valenciano", Boletín de la Sociedad Castellonense de Cultura, 68, 3, 1992, pp. 310-311, n. ${ }^{\circ}$ 2), de Santa Pola (Alicante), que se encuentra en el f. 29r del primer volumen del Diario, y DECar 228, obviamente de Carthago Nova, que Pérez Bayer anotó en el f. $54 \mathrm{r}$ del mismo volumen (y que detectaron ya Mas GaLvañ y ABASCAL, 1998, p. 110, n. ${ }^{\circ}$ 90).

86. Como las marcas de alfarero de fragmentos de terra sigillata de Santa Pola, registrados en el Ms. N. ${ }^{\circ}$ 5.953, f. 29r (Hernando SOBrino, M. ${ }^{a}$ R.: "Manuscritos de contenido epigráfico de la Biblioteca Nacional de Madrid: curiosidades y malentendidos", Gerión, 23, 2, 2005, p. 73).

87. Como una procedente de la ermita de Santa Eufemia de Castulo, en Jaén (Ms. n. ${ }^{\circ}$ 5953 , f. $145 \mathrm{r} / \mathrm{v}$ ), que creemos haber individualizado rectamente, pues había sido confundida con CIL II 3292 (Hernando Sobrino, 2005, pp. 73-74; de donde HEp 14, 2005, 189).

88. Carta a Juan A. Mayans de 19 de enero de 1785 (Mayans y SisCar, 1977, n. ${ }^{\circ} 285$, pp. 434-436).

89. MAYANS y Siscar, 1999, pp. 36-41, en especial n. 93. 
también daba el libro por perdido, se muestra especialmente contento ante esta noticia, señalando que debía darse a la luz pública de modo inmediato:

Siendo libro tan precioso, por contener muchíssimas inscripciones que ya no existen, quién puede dudar que deve comunicarse de contado al público, sin otra diligencia que un prólogo en que se refiera la suerte que ha experimentado esta obra sin esperar añadiduras, cotejos, colecciones, etc. En diez años se adelantaría más este estudio en España que en cinquenta ${ }^{90}$.

\section{Pérez Bayer como informador de Alejandro Javier Panel}

Ya nos hemos ocupado por extenso de la figura e importancia del jesuita francés Alejandro Javier Panel (Nozeroy 1699-Madrid 1764) en otro trabajo; baste mencionar aquí, para no resultar reiterativos, dos datos: primero, que el que sería preceptor de los infantes y Anticuario de la Real Librería tuvo la intención -como casi todos los eruditos de su tiempo, y casi con parejos resultados ${ }^{91}$ - de completar una colección de inscripciones latinas de España; segundo, que conocemos con cierta precisión la llegada de Panel a España (desembarcó en el puerto de Valencia en torno al 10 de junio de 1743) precisamente gracias a una carta enviada por Pérez Bayer a Mayans, carta en la que daba cuenta de la visita realizada por el recién llegado al arzobispo Mayoral ${ }^{92}$. Dicho de otro modo, Pérez Bayer y Panel se conocieron apenas arribado el último a la Península Ibérica.

Como ya señalamos en el referido trabajo monográfico, la relación de Pérez Bayer con Panel justifica por sí sola la pobre opinión que Mayans tenía de su paisano, a quien achacaba, además de una buena dosis

90. MAYANS y Siscar, 1977, n. ${ }^{\circ}$ 286, pp. 436-437. Ciertamente, nosotros no pudimos identificarla en los fondos manuscritos de la BNE y las búsquedas realizadas en el catálogo general de la misma Biblioteca no han dado ningún fruto, al menos de momento.

91. MORA, 1998, p. 66.

92. Véanse los detalles en Hernando Sobrino, 2017, p. 71. 
MARÍA DEL ROSARIO HERNANDO SOBRINO

FRANCISCO PÉREZ BAYER COMO INFORMADOR DE ALEJANDRO JAVIER PANEL

Y APUNTES SOBRE INSCRIPCIONES ROMANAS DE LA PROVINCIA DE SALAMANCA

de ignorancia y presunción ${ }^{93}$, poseer un "genio de veleta" ${ }^{94}$ o carecer de "espíritu de verdadero amigo" ". En los primeros compases de su relación con Panel, Pérez Bayer comunicaba al erudito de Oliva cuantas cartas recibía del jesuita y, además, sometía abiertamente sus propias respuestas, en latín, a su corrección y censura ${ }^{96}$; pero era obvio que el hebraísta, de cuya "flexibilidad" ya hemos dado cuenta supra, no iba a dejar pasar la oportunidad de establecer una relación que, en un futuro, podía resultarle provechosa, como de hecho lo fue para la obtención de la cátedra de hebreo en Salamanca ${ }^{97}$.

Así, y aunque a Mayans Panel nunca le resultó simpático, la relación entre Pérez Bayer y el jesuita fue fluida -y muy fructífera desde el punto de vista epigráfico, pese a que ambos fueran más aficionados a los estudios numismáticos- hasta 1754, fecha de la partida de Pérez Bayer a Roma; huelga decir que, una vez regresado a España, y por motivos que no es necesario ya explicar, las relaciones del valenciano con el jesuita se enfriaron y cambiaron de signo $^{98}$.

La interesante información relativa a la epigrafía hispana proporcionada por Pérez Bayer a Panel -que grosso modo puede acotarse en el periodo comprendido entre 1743 y 1754 , años correspondientes a la llegada del

93. Así se lo indica abiertamente a Burriel en sus francas cartas; podemos traer aquí, entre otras, la siguiente y prístina opinión que de su paisano expresa en una de ellas: «El concepto que yo tengo de él años ha es que tiene ingenio acompañado de alguna memoria i facilidad en aprender i maña en saber vender bueno científico a los ignorantes. I no más, porque sabe poco latín, aunque piensa que sabe mucho, i sabe poco porque ha leído poco i se ha egercitado menos. Pero de mí i de V.Rma. ha aprendido los nombres de los buenos autores i los cita como si los huviera visto" (MAYANS y SISCAR, 1972, n. ${ }^{\circ} 308$, pp. 608620, de 24 de abril de 1756).

94. Y más: "Es siempre de quien vence. Ya le he visto thomista acérrimo, ya suarista. Ya jesuita, ya pronto nos dirán que dominico, por no decir otra cosa" (carta de 24 de abril de 1756, de Mayans a Burriel; en MaYans y SisCar, 1972, n..$^{\circ}$ 308, pp. 619-620).

95. Carta a Martínez Pingarrón de 18 de febrero de 1769 (MAYANS y SISCAR, 1989, n. ${ }^{\circ}$ 137, pp. 182-183).

96. Véanse, por ejemplo, las cartas de 19 y 26 de febrero de 1744 (MAYans y Siscar, 1977 , n. ${ }^{\circ} 39$ y n. ${ }^{\circ} 40$, pp. $48-49$ y pp. $50-51$, respectivamente).

97. El apoyo prestado por Panel a Pérez Bayer para el acceso a la cátedra salmantina está fuera de duda, tal y como se deduce de una carta enviada por Burriel a Mayans el 9 de julio de 1746 (MAYANS y SISCAR, 1972, n. ${ }^{\circ}$ 73, p. 286).

98. Pese a lo dicho, sabemos que la comunicación entre ambos siguió activa al menos hasta 1761, tal y como puede deducirse de una carta enviada por Pérez Bayer a Juan de Santander y Zorrilla, con fecha de 13 de septiembre de dicho año (cf. Hernando SobRino, 2017, pp. 88-89). 
segundo a España y a la marcha del primero a Roma- puede organizarse en series bien diferenciadas ${ }^{99}$ :

1. Una primera, contenida en el Ms. 8729 de la BNE (pp. 569-575). Es el único manuscrito de Panel conocido por Hübner ${ }^{100}$ y al que, sin que sepamos muy bien cómo, se le perdió la pista, generando no pocas confusiones en la bibliografía especializada ${ }^{101}$. Este manuscrito, cuyo grueso dedicó Panel al vaciado de fuentes y repertorios bien conocidos ${ }^{102}$, contiene entre sus páginas finales un listado de 23 inscripciones que el jesuita explicita haber recibido de Pérez Bayer ("Perezius Panelio"). En la página 569 se registran, por orden de aparición, textos de Villajoyosa (CIL II 3577), de Rubielos de Mora (CIL II 3174) y de Denia (CIL II 3586); en la 570 de Denia (CIL II 3593) y de Ondara (CIL II 3597 y CIL II 3596); en la 571 de Játiva (CIL II 3622; CIL II 3620 y CIL II 3621), de Ondara (CIL II 3599) y de Mataró (CIL II 419* y CIL II 4612); en la 572 de Mataró (CIL II 4615) y de Barcelona (CIL II 4498; CIL II 4550); en la 573 de Barcelona (CIL II 4509), de Tarragona (CIL II 4314; CIL II 4419) y de Barcelona (CIL II 4521); en la 574 de Tortosa (CIL II 4064; CIL II 4065; CIL II 4055), y en la 575 de Tortosa (CIL II 4068; CIL II 4054 y CIL II 4061). La serie de inscripciones (algunas de las cuales, como indica expresamente Panel -que anota "ineditus" cuando procede-, eran efectivamente desconocidas en su momento) parece coincidir con la contenida en un manuscrito conservado en la Real Academia de la Historia, cuyo título reza: Varias inscripciones romanas halladas en diferentes pueblos del Reyno de Valencia y del Principado de Cataluña ${ }^{103}$.

99. Estas series no obedecen a un criterio cronológico, sino de ordenación del contenido epigráfico, téngase en cuenta.

100. Quien lo describió del siguiente modo: "....J suus in usus syllogen epigraphicam condidit, quam casu Matriti in nummophylacio regio detexit a. 1863 Iacobus Zobel. Est volumen grande paginarum 686, quod continet primum excerpta e Grutero (p. 1-355) et Muratorio (p. 361-565) usus nullius; deinde inscriptiones a Perezio (i.e. Bayéro) cum Panelio communicatas non multas (p. 569-575;Dertosanae sunt et Tarraconenses, ut dixi n. 75); sequuntur tituli aliquot Aegyptii a Sicardo missi Panelio (p. 576); Valerienses Andreae Burriel (p. 577-580; cf. p. 428); dissertatio de Roderici Cari scriptis (p. 581-593); denique indices epigraphici copiosissimi ( $p$. 601-686). Praeterea inest fasciculus solutus continens Alsinetii Emeritensia (cf.p. 54)" (CIL II, p. XXI, n. $\left.{ }^{\circ} 68\right)$.

101. Sobre el particular puede consultarse HERnando Sobrino, 2017, pp. 145-148, con las referencias bibliográficas previas referentes a este particular.

102. Descripciones del contenido completo de este manuscrito en HERnando Sobrino, 2009, pp. 315-333; id., 2017, pp. 106-110 y pp. 229-288.

103. El manuscrito, RAH 9-5676-2, ha sido individualizado ahora por ABASCAL y Cebrián, 2006, pp. 381-382, quienes lo fechan ca. 1745 y lo atribuyen sin duda a Pérez Bayer. Con anterioridad a este trabajo, formaba parte de un conjunto amplio cuyo título rezaba: Inscripciones tomadas de varios autores Romanas y Latinas igualmente inéditas, las más de ellas sepulcrales, muchas no se sabe dónde fueron halladas. Hay de Badajoz, 
Y APUNTES SOBRE INSCRIPCIONES ROMANAS DE LA PROVINCIA DE SALAMANCA

Aunque, como se puede advertir en su descripción del manuscrito, Hübner parece considerar que en el repertorio proporcionado por Pérez Bayer solo se registran textos de Dertosa y Tarragona, lo cierto es que a lo largo del corpus da cuenta de todas las de las localidades alicantinas, barcelonesas y valencianas. No obstante, y como ya tuvimos oportunidad de señalar, "ni están todas las que son, ni son tal y como se muestran en CIL II todas las que están" ${ }^{104}$.

Es más que posible presumir que los apuntes relativos a las inscripciones de las localidades alicantinas (Denia, Villajoyosa y Ondara) y de la valenciana Játiva daten de la época en que Pérez Bayer estuvo trabajando con el arzobispo Andrés Mayoral en Valencia (1738-1746), pues todas estas localidades pertenecían a la archidiócesis valenciana; para el caso de Ondara, además, contamos con la pertinente confirmación de esta sospecha en una carta remitida a Mayans desde Denia el 3 de septiembre de 1744:

Tengo copiadas tres inscripciones de Ondara que ahora no puedo aún remitir al Sr. D. Antonio. Quedo a la disposición de Vm. y a Dios que le guarde muchos años que deseo ${ }^{105}$.

Quizá también haya que situar en este mismo periodo el apunte de la inscripción de Rubielos de Mora (Teruel), localidad ajena a dicha archidiócesis, pero no muy lejana a la misma.

2. Una segunda, registrada en el Ms. 8914. Este manuscrito, de muy diferente factura al precedente, presenta el material ordenado por localidades de procedencia y, en consecuencia, las fichas epigráficas se presentan clasificadas siguiendo el orden alfabético del nombre latino, o latinizado, de dichas localidades ${ }^{106}$. La contribución de Pérez Bayer es destacada por Panel en numerosas fichas, casi todas ellas correspondientes a las inscripciones ya

Salvatierra, Parra, Halconera, Villagarcía, Frejenal, Jerez, Serpa, Mora, Arcos, Yelves, Valencia del Ventoso, Morera; en Extremadura y sus inmediaciones. En Valencia y en Cataluña, en Ondara, Villajoyosa, Denia, Xátiva, Tortosa, Mataró, Barcelona. En Castilla, Ciudad Rodrigo. En Alicante, Elche y sus inmediaciones. En Cartagena, Plasencia, Caparra, Medellin. Geographicas. Vxama, Clunia, Amaya, Hispalis, Clunia, Colonia Caritana, creo deba decir Caparitana, Otobesa, Sisili y Asota. Es un Códice en que se han recogido varias Inscripciones y antigüedades que me parecen copiadas por el sr. Vayer (Ms. RAH 9-5676, registrado y empleado por CORELl I VICENT, J.: Inscripcions romanes d'Ilici, Lucentum, Allon, Dianium i els seus territoris, Valencia, 1999). Como puede observarse en la secuencia que hemos destacado en negrita, la coincidencia es casi absoluta.

104. Hernando Sobrino, 2017, pp. 143-145.

105. MAYANS y SisCar, 1977, n. ${ }^{\circ}$ 51, pp. 62-64.

106. Descripciones detalladas de este manuscrito en Hernando Sobrino, 2009, pp. 336-342; id., 2017, pp. 117-119 у pp. 289-304. 
indicadas supra ${ }^{107}$; cierto es que faltan aquí los epígrafes de Barcelona y Tarragona, pero esta pérdida de información se ve compensada por la entrada, precisamente, de las piezas salmantinas que analizaremos infra. Además de enviar textos que, como ya se adelantó, eran inéditos en su momento, el valenciano comprobó sobre el terreno otros muchos que ya se encontraban anotados en otras otras fuentes, tales como las restantes piezas que registra Panel de Ondara, por solo citar un ejemplo ${ }^{108}$.

3. Una tercera, contenida en el Ms. 13369, el único que presenta el título original otorgado por el propio Panel: Augustorum Inscriptiones in Hispania; quae sunt, vel esse dicuntur ${ }^{109}$. El manuscrito, que también ha pasado desapercibido y/o confundido en la bibliografía más reciente, no es sino un catálogo de inscripciones dedicadas a los emperadores o ejecutadas en su nombre, un catálogo en el que se anotan, fundamentalmente, miliarios, inscripciones honoríficas, inscripciones votivas y termini augustales. La aportación de Pérez Bayer no tiene un peso numérico importante, pero sí es de calidad: no en vano Panel debe al hebraísta, además de diversas inscripciones procedentes de Valencia capital ${ }^{110}$, el apunte del miliario correspondiente a CIL II 4949 de Borriol ${ }^{111}$, que Hübner solo conoció a través de la obra del conde de Lumiares ${ }^{112}$, posterior en el tiempo, por tanto, al manuscrito del jesuita.

4. Una cuarta conservada en el Ms. 20275, manuscrito compuesto por tres cajas de schedae organizadas en 201 fascículos que respetan el orden primigenio concebido por Panel, formado sobre la base de las localidades de procedencia, cuyo nombre (que por lo común se ofrece en su versión latina) preside cada una de las fichas. Como ya tuvimos oportunidad de

107. Con la información aportada por Pérez Bayer se vinculan de modo expreso tres piezas de Mataró (las mismas vistas en el manuscrito precedente), cinco de Tortosa (CIL II 4054, CIL II 4055, CIL II 4061, CIL II 4064 y CIL II 4065; falta, pues, CIL II 4068, que sí se registra en el manuscrito previo), dos de Denia (las ya vistas), una de Ondara (CIL II 3596, igualmente registrada ya en el manuscrito precedente) y dos de Villajoyosa (CIL II 3571, que no constaba en el manuscrito precedente, y CIL II 3577), una de Gandía (CIL II 3605 , con la lectura del texto y, junto a ella, la restitución de Pérez Bayer), tres de Játiva (las mismas ya indicadas), y la de Rubielos de Mora.

108. CIL II 3596 y CIL II 3597.

109. Cf. Hernando Sobrino, 2017, p. 120 y pp. 305-314.

110. Así CIL II 3735 (p. 195), CIL II 3736 (p. 197) y CIL II 3734 (p. 199), de Valencia, para todas las cuales Panel indica "Vidit, exscripsit, misit D. Perez et Bayer". Se trata, en los tres casos, de inscripciones bien conocidas y con una larga cadena de transmisión, cadena en la que, sin embargo, en CIL II faltan los eslabones de Pérez Bayer o Panel.

111. Ms. 13369, p. 192.

112. Inscripciones y antigüedades del reyno de Valencia, redactada en 1805, publicada en Madrid en 1852. 
Y APUNTES SOBRE INSCRIPCIONES ROMANAS DE LA PROVINCIA DE SALAMANCA

destacar ${ }^{113}$, la aportación de Pérez Bayer en este manuscrito, al margen del apunte de algunas de las inscripciones levantinas ya vistas en los manuscritos previos, se concentra en los fascículos 23 y 24 , conservados en la caja $2 .^{a}$.

El primero de dichos fascículos corresponde a una carta autógrafa de Pérez Bayer (remitida desde Venecia el 14 de agosto de 1754) en la que este anuncia a Panel el envío adjunto de "las inscripciones de Barcelona y annotadas al margen las variantes"; las inscripciones aludidas son, en efecto, las que se encuentran en el fascículo 24: 47 epígrafes en total, 36 de Barcelona capital114, 8 de Tarragona ${ }^{115}$, 1 de San Ginés de Vilasar ${ }^{116}$, 1 de Isona $^{117}$ y 1 de Brescia (Italia) ${ }^{118}$, que el valenciano presenta, en su conjunto, como procedentes de la Ciudad Condal. Como tuvimos oportunidad de señalar en su momento ${ }^{119}$, entre estos apuntes -con los epígrafes cuidadosamente descritos, comentados, anotados y, en casos, dibujados por Pérez Bayer- se registran algunas inscripciones que han permanecido inéditas hasta fechas recientes ${ }^{120}$, así como otras para las que este manuscrito creemos constituye la primera y más antigua noticia al respecto de su existencia ${ }^{121}$.

\section{Apuntes de PÉREZ Bayer sobre ePígrafes salmantinos}

La aportación del hebraísta valenciano a la epigrafía salmantina no es, si la comparamos con la que proporcionó para el territorio levantino

113. Véase Hernando Sobrino, 2017, pp. 121-124, pp. 130-131 y pp. 315-346.

114. Por orden de aparición: CIL II 4521 (p. 1 del fascículo), CIL II 4498 (p. 3), CIL II 4506 (p. 4), CIL II 410* (p. 5), CIL II 4514 (pp. 7-8), CIL II 4523 (p. 9), CIL II 4524 (p. 10), CIL II 4505 (p. 12), CIL II 4554 (p. 14), CIL II 4568 (p. 15), CIL II 4529 (p. 16), CIL II 4504 (p. 17), CIL II 4497 (p. 18), CIL II 4517 (p. 19), CIL II 4515 (p. 20), CIL II $4522=4526$ (p. 22), CIL II 4546 (p. 23), CIL II 4538 (p. 24), CIL II 4542 (p. 25), CIL II 4545 (p. 26), CIL II 4536a (p. 27), CIL II 4548 (p. 28), CIL II 4547 (p. 29), CIL II 4539 (p. 30), IRC IV, 104 (p. 30), CIL II 4540 (p. 31), CIL II 4549 (p. 33), CIL II 4512 (p. 35), CIL II 4550 (p. 36), CIL II 4529 (p. 38), CIL II 4508 (p. 39), CIL II 4556 (p. 41), CIL II 411* (p. 42), CIL II $4509=6145$ (p. 44), CIL II 4507 (p. 45) y CIL II 4576 (p. 45).

115. CIL II 4150 (p. 6 del fascículo), CIL II 4151 (p. 11), CIL II $4518=6075$ (p. 13), CIL II 4377 (p. 21), CIL II 4234 (p. 37), CIL II 4241 (p. 40), CIL II 4419 (p. 43) y CIL II 4272 (p. 45).

116. CIL II 4528 (p. 32 del fascículo).

117. CIL II 4463 (p. 2 del fascículo).

118. CIL V 4653 (p. 34 del fascículo).

119. Véase Hernando Sobrino, 2017, pp. 153-155.

120. Como IRC IV, 104, de Barcino.

121. Así consideramos que ocurre con CIL II 4507 (=IRC IV, 27) y CIL II 4576 (=IRC IV, 179), ambas de Barcino, y CIL II $4272\left(=C I L I^{2} / 14,1211\right)$, de Tarraco. 
peninsular, numéricamente significativa, pero sí lo es, en efecto, desde una perspectiva cualitativa. Para comenzar porque, como ya hemos señalado en diferentes ocasiones, la documentación relativa al patrimonio epigráfico meseteño es, en términos proporcionales, escasísima en el conjunto de los manuscritos conservados en la BNE (lo que ya de por sí otorga importancia a estos apuntes) y, para continuar, porque se trata (y ello es lo verdaderamente importante) de apuntes de gran calidad.

Ya se ha adelantado que Pérez Bayer es señalado por Panel en el Ms. 8914 como informador directo al respecto de algunas inscripciones, todas ellas conocidas en su momento, procedentes de localidades diversas de la provincia de Salamanca; es hora de presentar sus apuntes con detalle:

\subsection{CIL II 865 (=HAE $1261=$ CIRPSa $^{122}$ 46=ERPSa ${ }^{123}$ 44), Ms. 8914, f. 117 (castro de Irueña, Fuenteguinaldo)}

Se trata, como puede comprobarse en la entrada pertinente del CIL II (Fig. 1), de un epígrafe bien conocido, que presenta una larga cadena de transmisión que arranca del siglo XvI (de la mano de Mariangelo Accursio) y que proseguirá sin solución de continuidad hasta el siglo xx.

Como puede apreciarse, Pérez Bayer aparece en dicha cadena de transmisión, pero no vinculado con Panel, sino con Velázquez (Luis José de Velázquez, más conocido como marqués de Valdeflores), con quien también mantuvo el valenciano contacto e intercambio en materia epigráfica. Extraña, llegados a este punto, que en su registro del epígrafe, entonces perdido, Hübner desechase algunos detalles del apunte de Pérez Bayer (quien, adviértase, es presentado como testigo ocular: "q(ui) v(idit)") y primase la información aportada por fuentes previas, como Accursio: no de otro modo pueden explicarse el innecesario espacio en blanco señalado entre ACCEI y CVM en línea 1 y la presentación del margen derecho de la pieza cortado, que implica la pérdida de texto en las líneas 2 y 3.

122. Alonso Ávila, A. y CRespo ORTiz de ZáRATE, S.: Inscripciones romanas de la provincia de Salamanca. Fuentes epigráficas para la historia social de Hispania romana. Valladolid, 1999.

123. Hernández Guerra, L.: Epigrafía de época romana de la provincia de Salamanca. Valladolid, 2001. 
MARÍA DEL ROSARIO HERNANDO SOBRINO

FRANCISCO PÉREZ BAYER COMO INFORMADOR DE ALEJANDRO JAVIER PANEL

Y APUNTES SOBRE INSCRIPCIONES ROMANAS DE LA PROVINCIA DE SALAMANCA

865 In eivitate Roderici, in aedo S. Bartholomaci, in parimento, marmoro oblongo, litteris ornatiwimis, allata inm ennis XX ex Uroognis villa procul lencis 4 (fortanae Ureiia) et queon olim urbem frisse opinantur Ace Augustobrigae nuxc cibdad Rodrigo, apad S. Bartholomenem in perimento templi Doc. 'Sobre la purta del jardin da la casa do los Chavos, al pasadizo, piedra de alabastro Cab. Ibi vidit Bryydr, postes peritit.

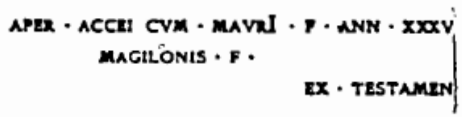

Arecrsies Fisp. XXVII 33 (indo Mur. 1635, 5 male); Docampo \&. 12 v.

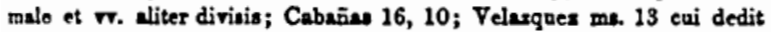
Bayir q. r.

1 accrlucvm Doc., Accervm - muvat - C Cab.; muvro correxit Mar., male. 2 mucroons Bayér. $3 \mathbf{x} \cdot$ testamento $\mathbf{r} \cdot c \cdot$ Bayér, ex - testan | $\cdot c$ Cab.

Fig. 1. CIL II 865

Es fácil advertir cómo en el cuidadoso apunte conservado en el Ms. 8914 (Fig. 2) -en el que se señalan correctamente las interpunciones y otros detalles de interés, como la I longa de línea 1- el genitivo de plural ACCEICVM se consigna sin espacio intermedio y, además, nada hace sospechar -ni por forma, ni por fondo- que la pieza esté rota y, en consecuencia, falte texto.

Dado que la inscripción estaba perdida en el momento de la redacción del CIL II, parece plausible suponer que al sabio alemán no le resultase convincente el extraño lugar que en el apunte de Pérez Bayer ocupa la abreviatura de la fórmula f(aciendum) c(uravit) que, en efecto, tendría más lógica al final de la línea 3.

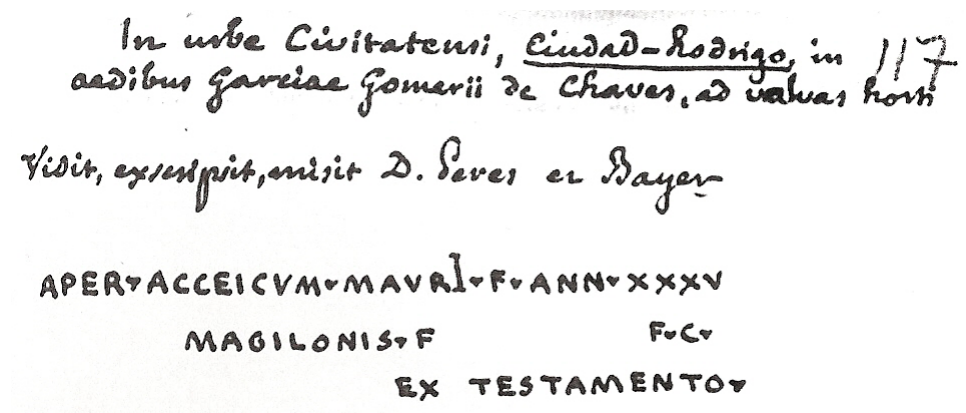

Fig. 2. CIL II 865 en el Ms. 8914, f. 117 
Ya indicaba Hübner que Pérez Bayer registraba para esta pieza la misma procedencia que ofrecía Antonio Sánchez Cabañas en su Historia de Ciudad Rodrigo, escrita en el siglo XVII (Fig. 3) ${ }^{124}$ :

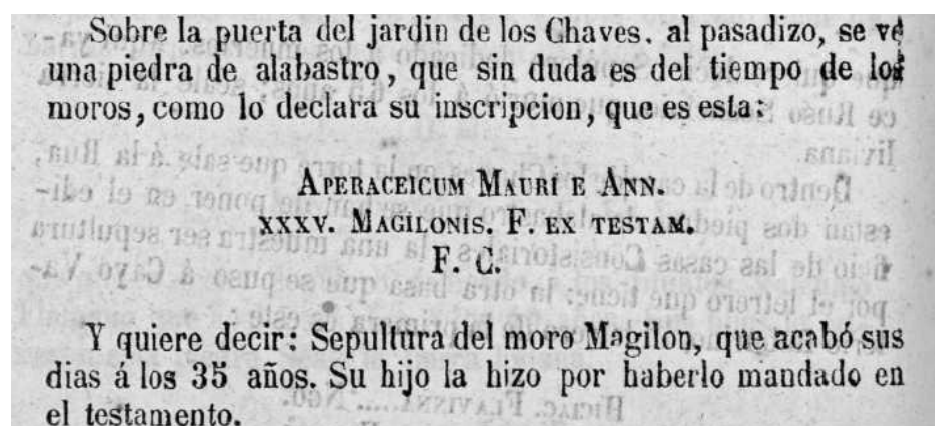

Fig. 3. CIL II 865 en Sánchez Cabañas (1861, p. 64)

La misma ubicación que, años después, refrendaría Fita en virtud de la información aportada por Román Marcos y Sánchez «á quien se debe el descubrimiento de este mármol blanco, original, que se creía perdido y que existe en Ciudad Rodrigo, en el edificio que fué "Casa de los Chaves" y ahora es Asilo de ancianos desamparados, sirviendo de miserable sostén á sacos de salvado; y corre peligro de deterioro y de sufrir otro lamentable extravío" ${ }^{125}$

Recuperada la inscripción, la fotografía aportada por Fita (Fig. 4) -que extrañamente no se ha vuelto a reproducir jamás, ni siquiera en los corpora de referencia existentes para el conjunto epigráfico de la provincia de Salamanca ${ }^{126}$ - permite dar por buena la puntuación de Pérez Bayer, si bien, y dado que presenta cortado su margen derecho, impide corroborar el final de las tres líneas (muy descentrada la tercera) de la inscripción.

124. Sánchez Cabañas, A.: Historia de Ciudad Rodrigo. Ciudad Rodrigo, 1861, imprenta nueva de Doña Carmen de Verdi, p. 64.

125. FiTA, F.: "Noticias", BRAH, 62, 1913, p. 400.

126. Esto es, CIRPSa 46 (si bien es cierto que esta serie jamás registra aparato gráfico) y ERPSa 44. 
MARÍA DEL ROSARIO HERNANDO SOBRINO

FRANCISCO PÉREZ BAYER COMO INFORMADOR DE ALEJANDRO JAVIER PANEL

Y APUNTES SOBRE INSCRIPCIONES ROMANAS DE LA PROVINCIA DE SALAMANCA

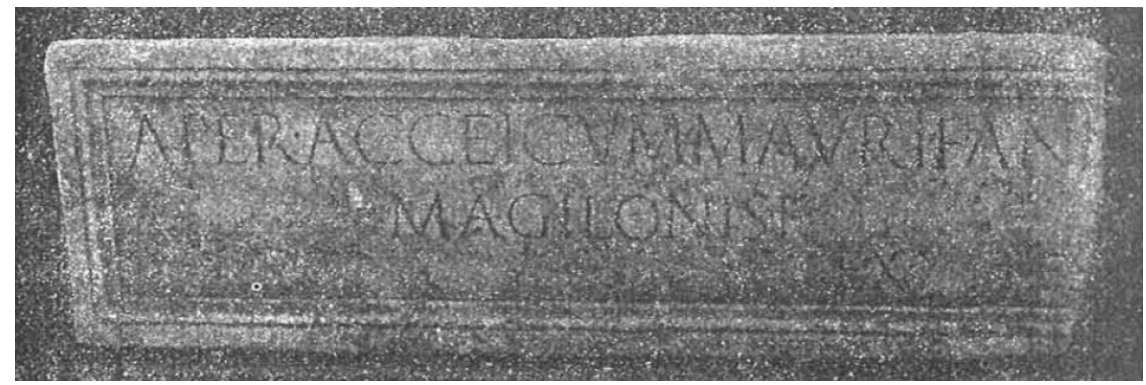

Fig. 4. CIL II 865 en Fita (1913, p. 400)

4.2. CIL II 860 (=CIRPSa 34=MRCL ${ }^{127} \quad 158=R S E R M S^{128} \quad 55=E R P S a$ 3), Ms. 8914, f. 118 (¿Ciudad Rodrigo?)

La cadena de transmisión de este epígrafe, como puede observarse en el registro del CIL II (Fig. 5), apenas si consta de un par de eslabones: parte del ya citado Sánchez Cabañas y, a través de Velázquez (nunca de Panel), se vincula con Pérez Bayer, tras el cual su pista se pierde.

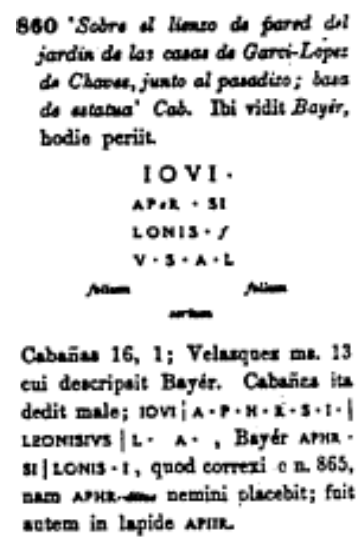

Fig. 5. CIL II 860

127. Crespo Ortiz de Zárate, S. y Alonso Ávila, A.: Manifestaciones religiosas del mundo antiguo en Hispania romana: el territorio de Castilla y León-I-. Las fuentes epigráficas. Valladolid, 1999.

128. Solana SÁINZ, J. M. y HeRnández GuerRa, L.: Religión y sociedad en época romana en la Meseta septentrional. Valladolid, 2000. 
En este caso, la deficiente lectura de Sánchez Cabañas (acompañada de una traducción e interpretación de su decoración decididamente "originales"; Fig. 6) ${ }^{129}$ debió de forzar a Hübner a guiarse del apunte de Pérez Bayer que, ofreciendo el mismo lugar de hallazgo para el epígrafe, presenta un texto extremadamente fiel al original (Fig. 7). Sin embargo, una vez más, la lectura proporcionada por Hübner no coincide plenamente con la registrada por el valenciano: obsérvese cómo, en la línea final, el orden de las iniciales de la fórmula canónica de las inscripciones votivas no concuerda con la ofrecida por Pérez Bayer, que es la correcta.

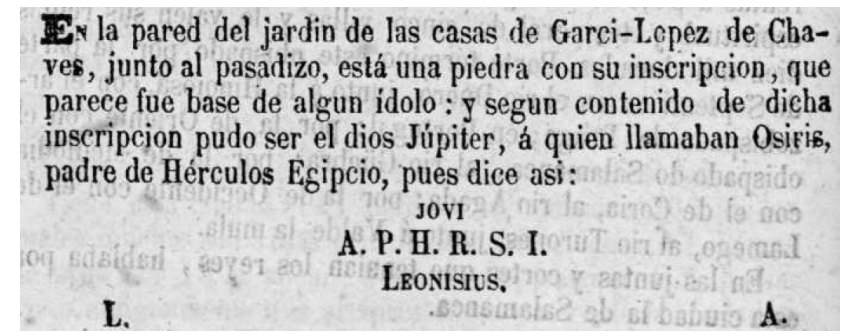

Fig. 6. CIL II 860 en Sánchez Cabañas (1861, p. 60)

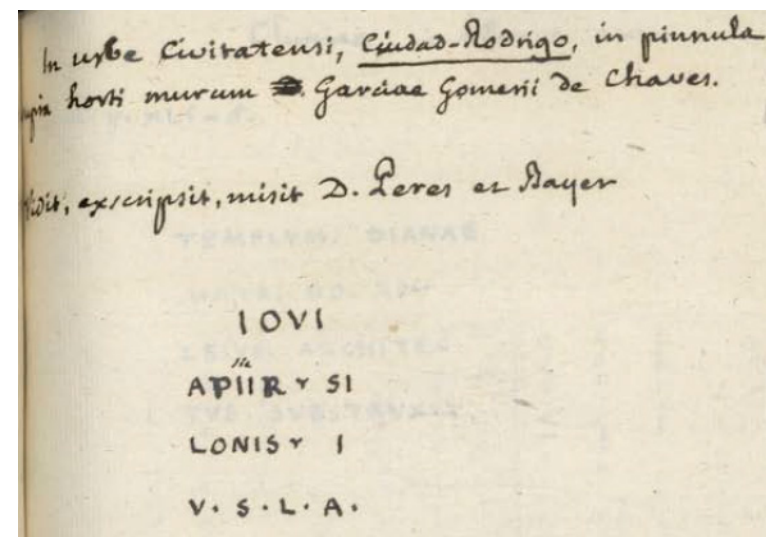

Fig. 7. CIL II 860 en el Ms. 8914, f. 118

Efectivamente, la recuperación del ara, acaecida en Ciudad Rodrigo en 1965, permite comprobar que la transcripción de Hübner, como bien

129. "Los amantes Lionisio y Lanica dedicaron esta estátua al dios Júpiter, con las cifras de sus dos corazones en medio de la luna, dando á entender por firme su lascivo amor" (SÁNCHez CaBAÑas, 1861, p. 61). 
advierte Martín Valls (Fig. 8), no era "del todo correcta" $"$, mientras que la de Pérez Bayer resulta impecable en todos sus detalles, incluidas las interpunciones triangulares.

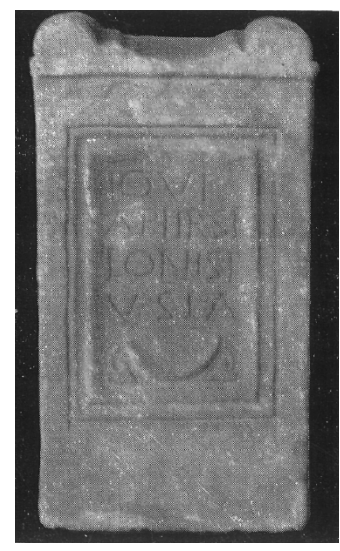

Fig. 8. CIL II 860 en Martín Valls (1965, lám. IV.4)

Nada nos ayuda este apunte a desentrañar el primigenio lugar de procedencia de este epígrafe, aspecto este que viene siendo objeto de discusión. El grueso de la historiografía considera, partiendo de las fuentes de Hübner, que procede de Ciudad Rodrigo ${ }^{131}$; no obstante, tomando en cuenta la noticia aportada por Fita, según el cual se habría "llevado a Ciudad Rodrigo desde las ruinas de Ureña, ${ }^{132}$, diversos investigadores consideran que, como la precedente, debe vincularse con Fuenteguinaldo ${ }^{133}$.

No obstante, dado que Fita ni argumenta su aserto -simplemente destaca la posibilidad de que el Aper de este epígrafe sea pariente del tocayo visto en el previo- ni lo vincula con fuente alguna que pueda contrastarse,

130. Martín Valls, R.: "Investigaciones arqueológicas en Ciudad Rodrigo", Zephyrus, 16, 1965, pp. 96-97. Este investigador incide de manera expresa en el detalle mencionado de la fórmula final: "Es interesante destacar que en todas las transcripciones las abreviaturas finales se leen V.S.A.L, de esta manera figura en el Corpus, donde Hübner la copia de autores anteriores; sin embargo, viendo el texto directamente se comprueba que no es así, sino V.S.L.A".

131. Así, entre otros, se señala en CIRPSa 34 y MRCL 158, y así se registra en las bases de datos HEPOL 21798 y EDCS 5500870.

132. Fita, F.: "La diócesis y fuero eclesiástico de Ciudad Rodrigo", BRAH, 61, 1912, pp. 446-447.

133. Caso de RSERMS 55 o de ERPSa 3. 
preferimos mantener la procedencia habitual, en espera de que nuevos datos puedan despejar esta duda.

\subsection{CIL II 874 (=CIRPSa 220=ERPSa 84), Ms. 8914, f. 362 (Salamanca)}

De nuevo nos encontramos aquí ante un texto escasamente documentado en el momento de confección del CIL II y en cuya cadena de transmisión se echa en falta, como puede observarse fácilmente (Fig. 9), a Pérez Bayer (extraña, de hecho, la ausencia de Velázquez).

Huelga decir que Pérez Bayer conoció la pieza - de la que además dio cuenta, "de memoria", en su célebre viaje ${ }^{134}-$ y que, en efecto, comunicó su lectura a Panel (Fig. 10), por lo que es sumamente raro que no se encuentre también entre los papeles legados por el marqués de Valdeflores.

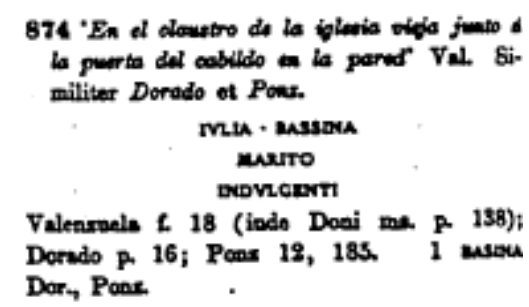

Fig. 9. CIL II 874

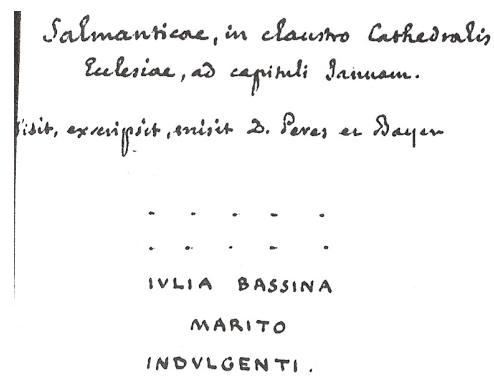

Fig. 10. CIL II 874 en el Ms. 8914, f. 362

134. Véase Ms. 5953, ff. 97r-/v. (=La Alhambra 3, 67, 1900, p. 440); la inscripción salmantina se cita a propósito de CIL II 2087 -de Granada, dedicada por P. Valerius Lucanus a su uxor indulgentissima - y se evoca como ejemplo de dedicatoria, inversa, entre esposos. 
Y APUNTES SOBRE INSCRIPCIONES ROMANAS DE LA PROVINCIA DE SALAMANCA

Sea como fuere, lo cierto es que la ficha conservada en el manuscrito de Panel permite de nuevo comprobar la calidad de las lecturas de Pérez Bayer; en este caso, no solo en lo tocante al texto y su puntuación, sino también, y ello no es menos importante, en lo relativo al estado de conservación de la pieza. Basta comparar la entrada del CIL II y el apunte del valenciano para comprobar que en la primera el epígrafe se ofrece como si estuviera completo, mientras que, en el segundo, los dos renglones iniciales de líneas intermitentes indican de forma clara que el epígrafe había perdido su parte superior.

La conservación de esta pieza -que continúa en el mismo lugar en que siempre fue vista, el claustro de la catedral de Salamanca- ha permitido constatar $^{135}$ que el epígrafe está efectivamente roto. Es de suponer, habida cuenta del texto conservado, que en las líneas iniciales constase, como mínimo, el nombre del marido a quien se dedicó.

\subsection{CIL II 880 (=CIRPSa 192=ERPSa 53), Ms. 8914, f. 395 (Miranda de Azán)}

La dependencia de Hübner de Pérez Bayer es, en este caso, absoluta; con el valenciano se vinculan, como puede comprobarse en la figura adjunta (Fig. 11), las dos fuentes registradas en el aparato crítico de CIL II 880: los manuscritos de Velázquez, de nuevo, y la España sagrada del padre Flórez ${ }^{136}$. Una vez más falta aquí Panel a quien, sin embargo, le llegó también la pertinente comunicación al respecto (Fig. 12).

135. Si nuestros datos son correctos, solo ERPSa 84 (publicado en 2001) indica la falta de texto en la parte superior de la pieza; en los restantes trabajos (incluido CIRPSa 220) se mantiene la lectura en los términos registrados por Hübner.

136. Quien, efectivamente, señaló: "que copió y me comunicó el Doctor Pérez Bayer" (FLóREZ, 1758,. p. 271). 


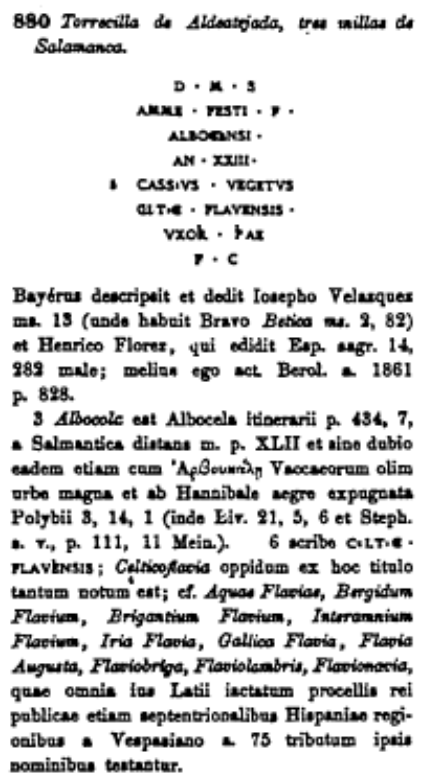

Fig. 11. CIL II 880

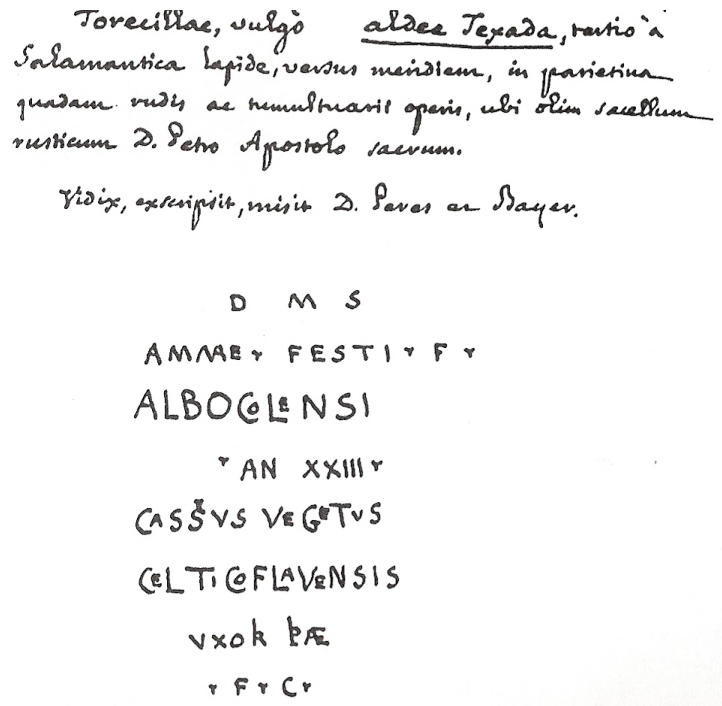

Fig. 12. CIL II 880 en el Ms. 8914, f. 395 
Dado que la pieza se encuentra perdida ${ }^{137}$, los datos aportados por Pérez Bayer -cuyo apunte es extremadamente detallado- resultan de gran interés. Como bien se anota en CIL II 880, el epígrafe procedía de Torrecilla de Aldeatejada, un despoblado perteneciente al término municipal de Miranda de Azán, sito al sur de Salamanca ${ }^{138}$ e inmejorablemente dispuesto con respecto a la célebre vía de la Plata; no obstante, Hübner no proporciona la ubicación exacta de la pieza que, como se puede advertir, aparece explícita en el apunte transmitido por Panel: formaba parte de una pared construida en el lugar donde previamente se asentaba la capilla de San Pedro Apóstol.

Como se deduce del cotejo de ambos registros, la inscripción no varía en lo sustancial, aunque sí en algunos detalles. No coincide, en efecto, su puntuación, extremo que puede observarse en casi todas las líneas, comenzando ya por la inicial; en este sentido, y tal y como se aprecia en la Fig. 13, la puntuación ofrecida por Flórez se ajusta más, sin amoldarse completamente, a la anotada por Pérez Bayer en el apunte de Panel.

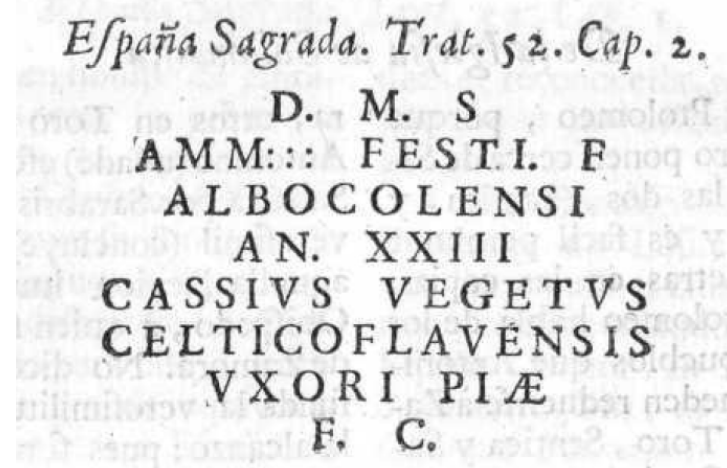

Fig. 13. CIL II 800 en Flórez (1758, p. 272)

137. El padre Morán, que conoce el epígrafe tanto a través de Flórez como de Hübner (Morán, C.: Investigaciones acerca de arqueología y prehistoria de la región salmantina. Salamanca, 1919, pp. 102-103), ya no pudo encontrarla, según él mismo confiesa (Morán, C.: Reseña histórico-artística de la provincia de Salamanca (Acta Salmanticensia II/1). Salamanca, 1946, p. 85).

138. Así podemos leerlo en el diccionario de Madoz, voces "Miranda de Azán" (cf. Madoz, P.: Diccionario geográfico-estadístico-bistórico de España y sus posesiones de ultramar. Madrid, imprenta del Diccionario Geográfico, tomo XI, 1848, p. 433) y "Torrecilla de Aldea Tejada" (id., tomo XV, 1849, p. 75), en la última de las cuales se registra como alquería poblada por "un vecino y dos almas" (??). 
Del mismo modo, en la línea 2 CIL II 880 registra AMME (lectura adoptada por toda la historiografía posterior), cuando en el apunte de Pérez Bayer es claro el nexo AE, de suerte que debe leerse AMMAE, sin monoptongación de la desinencia del dativo. Tampoco anota Hübner el nexo AE en el último término de línea 7 -detalle que sí señala Flórez- ofreciendo en este caso PIAE.

\section{Conclusiones}

El contacto que, en materia epigráfica, mantuvieron el padre Panel y Pérez Bayer fue, en efecto, muy fructífero. Gracias al valenciano el jesuita francés pudo conocer una nutrida serie de inscripciones -muchas de ellas inéditas en el momento de su comunicación- que pasaron a engrosar su más que notable corpus, un corpus que no por inconcluso es menos importante.

El examen concreto de las cuatro inscripciones de la actual provincia de Salamanca transmitidas por Pérez Bayer a Panel nos ha permitido poner de relieve la gran calidad de los apuntes epigráficos del valenciano, todos los cuales hacen gala de un gran esmero y atención al detalle. Pero no las hemos traído aquí tanto para demostrar este extremo, del que la investigación, como hemos tenido oportunidad de resaltar en los capítulos previos, no ha dudado jamás, como para destacar, una vez más, la necesidad de revisar las fuentes de que se nutrió CIL II.

De un lado, estos apuntes vuelven a poner en evidencia la necesidad de integrar a Panel en la cadena de transmisión de determinados epígrafes en los que su nombre jamás se ha insertado; de otro, creemos servirán para completar y perfilar el conocimiento de las cuatro inscripciones salmantinas, una de ellas perdida en la actualidad, para las que el testimonio de Pérez Bayer, a través de Panel, proporciona detalles de indudable interés.

\section{ABREVIATURAS}

CIL II: E. HÜBNER, Corpus Inscriptionum Latinarum II. Inscriptiones Hispaniae Latinae, Berlín, 1869. Inscriptionum Hispaniae Latinarum Supplementum, Berlín, 1892.

CIL II $2 / 14:$ G. AlFÖLDY, ed., Corpus Inscriptionum Latinarum II: Inscriptiones Hispaniae Latinae, ed. altera, pars XIV, fasciculus II. Colonia Iulia Urbs Triumphalis Tarraco, Berlín-Nueva York, 2011. Fasciculus III. Colonia Iulia Urbs Triumphalis Tarraco, Berlín-Boston, 
MARÍA DEL ROSARIO HERNANDO SOBRINO

FRANCISCO PÉREZ BAYER COMO INFORMADOR DE ALEJANDRO JAVIER PANEL

Y APUNTES SOBRE INSCRIPCIONES ROMANAS DE LA PROVINCIA DE SALAMANCA

2012. Fasciculus IV. Colonia Iulia Urbs Triumphalis Tarraco, BerlínNueva York, Berlín-Boston, 2016.

CirPSa: A. Alonso Ávila y S. Crespo Ortiz de Zárate: Inscripciones romanas de la provincia de Salamanca. Fuentes epigráficas para la historia social de Hispania romana, Valladolid, 1999.

ERPSa: L. HERNÁNDEZ GuERRA, Epigrafía de época romana de la provincia de Salamanca, Valladolid, 2001.

ERSg: J. Santos Yanguas, Á. L. Hoces de la Guardia Bermejo y J. Del Hoyo, Epigrafia romana de Segovia y su provincia, Segovia, 2005.

IRC IV: G. FABRE, M. MAYER y I. RODÀ, Inscriptions romaines de Catalogne IV. Barcino, París, 1997.

IRST'2: J. CORELl i Vicent, J. (X. Gómez i Font, col.), Inscripcions romanes del País Valencià III. (Saetabis i el seu territori), Valencia, 2006.

MLH: J. Untermann, Monumenta Linguarum Hispanicarum. Band III: Die iberischen Inschriften aus Spanien. 2. Die Inschriften, Wiesbaden, 1990.

mRCL: S. Crespo Ortiz de ZÁrate y A. Alonso Ávila, Manifestaciones religiosas del mundo antiguo en Hispania romana: el territorio de Castilla y León-I-. Las fuentes epigráficas, Valladolid, 1999.

RSERMS: J. M. SOLANA SÁINZ y L. HERNÁNDEZ GUERRA, Religión y sociedad en época romana en la Meseta septentrional, Valladolid, 2000.

\section{BIBLIOGRAFÍA}

Abascal, J. M. y Cebrián, R. (2006): Manuscritos sobre Antigüedades de la Real Academia de la Historia (Real Academia de la Historia. Publicaciones del Gabinete de Antigüedades. Antiquaria Hispanica 12), Madrid.

Aguilar Piñal, F. (1991): Bibliografía de autores españoles del siglo XVIII, Madrid, vol. VI, 360-362.

Álvarez Barrientos, J. y Mora Rodríguez, G. (1985): «El final de una tradición. Las falsificaciones granadinas del siglo XVIII", Revista de Dialectologia y Tradiciones populares, 40, 163-189.

Álvarez De Morales, A. (1983): "Pérez Bayer y su viaje a Andalucía en 1782", [en] Actas del II Coloquio de Historia de Andalucía Moderna, Córdoba, 185-197.

Blanco, P. (1929): "Los manuscritos hebreos de la Biblioteca de El Escorial", BRAH, 95, 477-520.

CABeza SÁnCheZ-Albornoz, M. C. (1994): "Índice de los manuscritos donados por Pérez Bayer a la Universidad de Valencia", [en] S. Celestino Agudo (ed.), De libros y bibliotecas. Homenaje a Rocío Caracuel, Sevilla, 57-72. 
Caro Baroja, J. (1992): Las falsificaciones de la Historia, Madrid.

Casanovas Miró, J. (2005): Epigrafía bebrea (=Real Academia de la Historia. Catálogo del Gabinete de Antigüedades I. Antigüedades 1.1.5), Madrid.

Casanovas, I. y Batllori, M. (1969): Josep Finestres. Epistolari, suplement, Barcelona.

Catalá Sanz, J. A. (2001): "Pérez Bayer después del viaje a Italia”, Estudis, $27,229-245$.

Corell i Vicent, J. (1999): Inscripcions romanes d'Ilici, Lucentum, Allon, Dianium $i$ els seus territoris, Valencia.

COREll i Vicent, J. y Gómez i Font, X. (1992): "Inscripciones romanas del país Valenciano", Boletín de la Sociedad Castellonense de Cultura, 68/3, 309-333.

FinestRes, J. (1762): Sylloge inscriptionum romanarum, quae in principatu Catalauniae vel extant vel aliquando extiterunt, Cervera, imprenta de Ibarra.

Fita, F. (1912): "La diócesis y fuero eclesiástico de Ciudad Rodrigo", BRAH, 61, 437-448.

FITA, F. (1913): "Noticias», BRAH, 62, 395-400.

FLóREZ, E. (1751): España sagrada. Theatro geographico-bistorico de la iglesia de España. Origen, divisiones, y limites de todas sus Provincias. Antiguedad, Traslaciones, y estado antiguo de sus Sillas con varias dissertacioes criticas. Tomo VII. De las iglesias sufraganeas antiguas de Toledo: Acci, Arcavica, Basti, Beacia, Bigastro, Castulo, Compluto, Dianio, Elotana, Ilici, Mentesa, Oreto y Osma, segun su estado antiguo, Madrid, oficina de Antonio Marín.

Flórez, E. (1758): España sagrada. Theatro geographico-bistorico de la iglesia de España. Origen, divisiones, y limites de todas sus Provincias. Antiguedad, Traslaciones, y estado antiguo de sus Sillas con varias dissertacioes criticas. Tomo XIV. De las iglesias de Abila, Caliabria, Coria, Coimbra, Ebora, Egitania, Lamego, Lisboa, Ossonoba, Pacense, Salamanca, Viséo y Zamora, segun su estado antiguo, Tomo XIV, Madrid, oficina de Antonio Marín.

García Ejarque, L. (1997): La Real Biblioteca de S. M. y su personal (17121836), Madrid.

Gimeno Pascual, H. (2012): "Los estudios epigráficos en España en el siglo XVIII", [en] M. Almagro-Gorbea y J. Maier Allende (eds.), De Pompeya al nuevo mundo. La Corona española y la Arqueología en el siglo XVIII (Real Academia de la Historia. Publicaciones del Gabinete Antigüedades, Antiquaria Hispanica 23), Madrid, 143-156. 
MARÍA DEL ROSARIO HERNANDO SOBRINO

FRANCISCO PÉREZ BAYER COMO INFORMADOR DE ALEJANDRO JAVIER PANEL

Y APUNTES SOBRE INSCRIPCIONES ROMANAS DE LA PROVINCIA DE SALAMANCA

Godoy Alcántara, J. (1868): Historia crítica de los falsos Cronicones, Madrid.

Gómez de la SeRna, G. (1974): Los viajeros de la Ilustración, Madrid.

GRUTERO, J. (1603): Inscriptiones antiquae totius orbis Romani in corpus absolutissimi redactae, Heidelberg.

Guglieri VázQuez, J. I. (1992): Manuel Martí, latinista y autor latino, tesis doctoral, Universidad Complutense de Madrid.

Hernando Sobrino, M. ${ }^{a}$ R. (2005): "Manuscritos de contenido epigráfico de la Biblioteca Nacional de Madrid: curiosidades y malentendidos", Gerión, 23/2, 59-88.

Hernando Sobrino, M. ${ }^{a}$ R. (2006): "Manuel Martí o la legitimación del documento epigráfico", Cuadernos de Filología Clásica. Estudios Latinos, 26/2, 193-208.

Hernando Sobrino, M. ${ }^{a}$ R. (2009): Manuscritos de contenido epigráfico de la Biblioteca Nacional de Madrid (siglos XVI-XX). La transmisión de la inscripciones de la Hispania romana y visigoda, Madrid.

HERnANDo Sobrino, M. ${ }^{a}$ R. (2017): Alejandro Javier Panel (1699-1764) y la epigrafía hispana. Un jesuita francés en el "infierno abreviado" (Ausonius. Scripta Receptoria 11), Bordeaux.

Jimeno, V. (1747-1749): Escritores del reyno de Valencia, chronologicamente ordenados desde el año de MCCXXXVIII de la Christiana conquista de la misma Ciudad, hasta el de MDCCXLVII, Valencia, 2 vols., imprenta de José E. Dolz.

Juan García, L. (1918): Pérez Bayer y Salamanca. Datos para la biobibliografía del hebraista valenciano, Salamanca.

Lastanosa, V. J. (1645): Museo de las medallas desconocidas españolas, Huesca, imprenta de Juan Nogues.

Leite de Vasconcellos, J. (1920): «Viagem de Pérez Bayer em Portugal, em 1782", O Arqueólogo Portugués, 24, 108-176.

López FonsecA, A. (2008): "La formación clásica de Francisco Pérez Bayer y los proyectos ilustrados: Ensayo, erudición y crítica en el siglo XVIII español", Torre de los Lujanes, 63, 171-189.

Lumiares, Conde de $\rightarrow$ Valcárcel Pío de Saboya y Moura, A.

MADOZ, P. (1845-50): Diccionario geográfico-estadístico-histórico de España y sus posesiones de ultramar, Madrid, imprenta del Diccionario Geográfico.

MAFFEI, S. (1749): Museum veronense hoc est antiquarum inscriptionum atque anaglyphorum collectio cui Taurinensis adiungitur et Vindobonensis. Accedunt monumenta id genus plurima nondum vulgata, et ubicumque collecta, Verona. 
MARTín VALLS, R. (1965): "Investigaciones arqueológicas en Ciudad Rodrigo", Zephyrus, 16, 71-98.

Mas Galvañ, C. y Abascal J. M. (1998): «El viaje literario de Francisco Pérez Bayer por Valencia y Murcia (1782)", Saitabi, 48, 79-111.

Mateu y Llopis, F. (1931): "Pérez Bayer i les inscripcions ibèriques i hebraiques de Molvedre", Boletín de la Sociedad Castellonense de Cultura, 12, 248-257.

Mateu y Llopis, F. (1953): En torno de Pérez Bayer, numismata y bibliotecario, Discurso de ingreso en el Centro de Cultura Valenciana, 30 de noviembre de 1950, Valencia.

MaYANS y SISCAR, G. (1972): Epistolario, II: Mayans y Burriel, Valencia [transcripción, notas y estudio preliminar A. Mestre].

Mayans y Siscar, G. (1976): Epistolario, V: Escritos económicos, Valencia [estudio preliminar de E. Lluch, selección, transcripción y notas de A. Mestre Sanchís].

MaYans y SiscaR, G. (1977): Epistolario, VI: Mayans y Pérez Bayer, Valencia [transcripción, notas y estudio preliminar A. Mestre Sanchís].

MaYANS y SisCAR, G. (1987): Epistolario, VII: Mayans y Martínez Pingarrón, 1: Historia cultural de la Real Librería, Valencia [transcripción, estudio preliminar y notas A. Mestre].

MAYANS y SISCAR, G. (1988): Epistolario, VIII: Mayans y Martinez Pingarrón, 2: Los Manteístas y la cultura ilustrada, Valencia [transcripción, estudio preliminar y notas A. Mestre].

MAYANS y SISCAR, G. (1989): Epistolario, IX: Mayans y Martinez Pingarrón, 3: Real Librería y política cultural, Valencia [transcripción, estudio preliminar y notas A. Mestre].

MAYANS y SISCAR, G. (1999): Introductio ad veterum inscriptionum historiam literariam (=Real Academia de la Historia. Publicaciones del Gabinete de Antigüedades. Estudios 4), Madrid [traducción y ed. crítica L. Abad Casal y J. M. Abascal Palazón].

Mestre Sanchís, A., Pérez García, P. y Catalá Sanz, J. A. (eds.), (1998): Francisco Pérez Bayer. Viajes literarios (Arxius i Documents 22), Valencia.

Mora, G. (1998): Historias de mármol. La arqueología clásica española en el siglo XVIII (=Anejos de AEspA 18), Madrid.

Mora, G. (2003): "La "erudita peregrinación". El viaje arqueológico de Francisco Pérez Bayer a Italia (1754-1759)", [en] J. Beltrán Fortes et alii (eds.), Illuminismo e Ilustración. Le antichità e i loro protagonisti in Spagna e in Italia nel XVIII secolo (Bibliotheca Italica, Monografías de la Escuela Española de Historia y Arqueología en Roma 27), Roma, $255-275$. 
MARÍA DEL ROSARIO HERNANDO SOBRINO

FRANCISCO PÉREZ BAYER COMO INFORMADOR DE ALEJANDRO JAVIER PANEL

Y APUNTES SOBRE INSCRIPCIONES ROMANAS DE LA PROVINCIA DE SALAMANCA

Mora, G. (2004): "Francisco Pérez Bayer», [en] M. Ayarzagüena Sanz y G. Mora (eds.), Pioneros de la arqueología en España. Del siglo XVI a 1912 (Zona Arqueológica 3), Alcalá de Henares, 47-49.

Mora, G. (2009): "Pérez Bayer, Francisco", [en] M. Díaz-Andreu, G. Mora y J. CORTADElla (coords.), Diccionario histórico de la Arqueología en España (siglos XV-XX), Madrid, 515-517.

Mora, G. (2010): «Los estudios hebraicos en la España ilustrada. Francisco Pérez Bayer y el origen de las lenguas y escrituras antiguas de España", [en] A. J. Domínguez Monedero y G. Mora Rodríguez (eds.), Doctrina a magistro discipulis tradita. Estudios en homenaje al profesor Dr. Luis García Iglesias, Madrid, 425-454.

Morán, C. (1919): Investigaciones acerca de arqueología y prebistoria de la región salmantina, Salamanca.

Morán, C. (1946): Reseña histórico-artística de la provincia de Salamanca (Acta Salmanticensia II/1), Salamanca.

Muratori, L. A. (1739-1742): Novus thesaurus veterum inscriptionum in praecipuis earundem collectionibus hactenus praetermissarum, Milán, 4 vols.

Orfila, M., Sotomayor, M., Sánchez, E., Marín, P. y Sánchez, C. (2012): La Granada "falsificada": el picaro Juan de Flores, Granada.

PASTOR Fuster, J. (1829): Elogio histórico y bibliográfico del ilustrísimo señor Don Francisco Pérez Bayer, del Consejo y Cámara de Castilla, caballero pensionado de la Real y distinguida Orden de Carlos III, preceptor de los serenísimos Infantes, arcediano mayor y canónigo de Valencia y bibliotecario de su Majestad, Valencia, imprenta de Ildefonso Mompié (facsímil 1991).

Pastor Fuster, J. (1830): Biblioteca Valenciana de los escritores que florecieron hasta nuestros dias y que aún viven. Con adiciones $y$ enmiendas á la de D. Vicente Ximeno. Tomo segundo, Valencia, imprenta de Ildefonso Mompié.

Pérez BAYer, F. (1752): De toletano hebraeorum templo, Biblioteca Nacional de España, Mss. 8260 y 9296.

Pérez BAYer, F. (1753): Reges Tharsis et insulae. Pro explanatione Davidici Psalmi: Deus iudicium tuum Regi da Ec. ad amplissimum almae Barcinonensis Ecclesiae canonicorum collegium oratio postridie fest. S. Lucae XIV kal. Nov. salutis MDCCLIII habita, Barcelona, imprenta de Pablo Nadal.

PÉrez BAYER, F. (1756): Damasus et Laurentius hispanis asserti et vindicati, Roma, imprenta de Giuseppe y Filippo de Rossi.

PÉrez BAYER, F. (1772): "Del alfabeto y lengua de los fenices y de sus colonias. Para ilustracion de un lugar de Salustio, en que hablando 
de la ciudad de Leptis, dice: Eius ciuitatis lingua modò conuersa connubio Numidarum. Iugurth. LXXVII", [en] D. GABRIEL DE BORBÓN, La conjuracion de Catilina y la guerra de Jugurta por Cayo Salustio Crispo, Madrid, imprenta de Joaquín Ibarra, 337-378.

Pérez BAYer, F. (1774-1780? [1991]): Por la libertad de la literatura española, Alicante [estudio preliminar A. Mestre Sanchís].

PÉREZ BAYER, F. (1781): De numis hebraeo-samaritanis Dissertatio Isagogica ad tractatum de Phenicum et Graecorum in Hispania Nummis quos incognitos vocant, Valencia, imprenta de Benito Monfort.

Pérez Bayer, F. (1782): Diario del viaje desde Valencia a Andalucía y Portugal hecho por Don Francisco Perez Bayer en el año de 1782, Biblioteca Nacional de España, Mss. 5953-5954 (copia).

PÉREZ BAYER, F. (1790): Numorum bebraeo-samaritanorum vindiciae, Valencia, imprenta de Benito Monfort.

PÉREZ BAYER, F. (1793): Legitimidad de las monedas hebreo-samaritanas. Confutación, Valencia, imprenta de Benito Monfort.

Piwnik, M.-H. (1983): «Les deux voyages de F. Pérez Bayer au Portugal. 1782, 1783", Revista de Historia Moderna, 3, 261-317.

Razón del juicio: Razón del juicio seguido en la ciudad de Granada ante los ilustrisimo señores Don Manuel Doz, presidente de su Real Chancilleria; Don Pedro Antonio Barroeta y Angel, Arzobispo de que fue de esta diocesis y Don Antonio Jorge Galvan, actual sucesor en la Mitra, todos del Consejo de su Majestad: contra varios falsificadores de escrituras públicas, monumentos sagrados, y profanos, caracteres, tradiciones, reliquias, y libros de supuesta antigüedad, Madrid, 1781, imprenta de Joaquín Ibarra.

Rubio Paredes, J. M. (1990): “Cartagena en el "Viaje literario" de Pérez Bayer", Murgetana, 81, 91-104.

Salas Álvarez, J. (2007): "El Viaje arqueológico a Andalucía y Portugal de Francisco Pérez Bayer", Spal, 16, 9-24.

Sánchez Cabañas, A. (1861): Historia de Ciudad Rodrigo, Ciudad Rodrigo, imprenta nueva de Doña Carmen de Verdi.

Sempere y Guarinos, J. (1785): Ensayo de una biblioteca española de los mejores escritores del reinado de Carlos III, Madrid (facsímil, Salamanca, 1997).

Sidro Vilarroig, J. F. (1797): In funere Francisci Perezii Bayerii : Oratio ad senat. et acad. Valentinam habita, Valencia, imprenta de Benito Monfort.

SotomaYor, M. (1986): "Excavaciones arqueológicas en la Alcazaba de Granada (1754-1763)", [en] Miscelánea Augusto Segovia, Granada, 243283. 
SOTOMAYOR, M. (1988): Cultura y picaresca en la Granada de la Ilustración. D. Juan de Flores y Oddouz, Granada.

Tyschen, O. G. (1786): Carta latina del señor D. Olao Gerardo Tyschen al Ilmo. Sr. D. Francisco Pérez Bayer con su traducción castellana. Se añade refutación de los argumentos de dicho Señor Bayer en favor de las monedas samaritanas, atribuida al mismo Sr. Tyschen, Madrid, imprenta de la Viudad de Ibarra.

VÁlCARCel Pío de Saboya y Moura, A. (1852): Inscripciones y antigüedades del reyno de Valencia, Madrid.

Vegué y Goldoni, A. (1934): "Para la historia de la arqueología en España. El canónigo Pérez Bayer y los Nuevos Monumentos de Granada", Anuario del Cuerpo de Facultativos de Archiveros, Bibliotecarios y Arqueólogos, 2, 25-51.

VelázQuez de Velasco, L. J. (1752): Ensayo sobre los alphabetos de las letras desconocidas que se encuentran en las mas antiguas Medallas, y Monumentos de España, Madrid, imprenta de Antonio Sanz.

VIDAL, J. (2013): "Francisco Pérez Bayer y los estudios de epigrafía fenicia", Aula Orientalis, 31/2, 323-332. 
